\title{
Expression Systems: Pichia pastoris
}

Fatima Alkhalfioui, Christel Logez, Olivier Bornert, and Renaud Wagner

3.1

Introduction

Among the most widespread, popular, effective, and inexpensive microorganisms developed for heterologous expression, Pichia pastoris has become a system of choice not only for the production of cytosoluble and industrially relevant proteins, but also for a growing panel of eukaryotic membrane proteins expressed at levels compatible with structural studies. Up to now indeed, more than 150 different representative membrane proteins have been expressed in $P$. pastoris and this has led to the acquisition of high-resolution structures for a dozen of them, making $P$. pastoris one of the most performant heterologous expression system for the structural studies of eukaryotic membrane proteins. This chapter gives a global overview on (i) how the P. pastoris system basically operates, (ii) how it performs for the recombinant expression of membrane proteins, and (iii) the different strategies and tips that can be applied to improve the system.

3.2

A (Brief) Summary on the (Long) History of $P$. pastoris

P. pastoris is an ascosporous yeast that is naturally present in tree fluxes from European and north American forests [1]. It was first isolated in 1919 in France from the exudate of a chestnut tree [2] and half a century later was described for its ability to use methanol as a sole carbon source [3]. From this time point, the potential of $P$. pastoris for biotechnological applications has been continuously explored both in industry and academia. While its use as a potential source of single-cell protein for animal feed did not meet the expected economic viability [4], this yeast was rapidly recognized as a remarkable production platform for a wide class and number of heterologous proteins, and up to now more than 500 candidates have been successfully recombinantly expressed in this system (reviewed in [5, 6] among others), several of them being biopharmaceuticals already on the market. Recently, phylogenetic analyses based on rRNA sequence

Production of Membrane Proteins: Strategies for Expression and Isolation, First Edition.

Edited by Anne Skaja Robinson.

(C) 2011 Wiley-VCH Verlag GmbH \& Co. KGaA. Published 2011 by Wiley-VCH Verlag GmbH \& Co. KGaA. 
comparisons led to the transfer of Pichia pastoris into the Komagataella genus [7], and the commonly used biotechnological strains are now classified into two dinstinct species, K. pastoris and K. phaffii [8]. The saga of this special yeast, that we will continue to call $P$. pastoris for the sake of simplicity, will be certainly boosted in the coming years after the very recent release of its genome sequence [9]. This new wealth of information will indeed open new possibilities for the engineering of enhanced biotechnological strains.

\section{3}

\section{Introducing P. pastoris as a Biotechnological Tool: Its (Extended) Strengths and (Limited) Weaknesses}

The success of $P$. pastoris as an efficient protein factory is attributable to a series of advantages related to both its yeast nature and its particular methylotrophic metabolism. This organism indeed presents a short generation time $(2 \mathrm{~h})$, grows on very simple and inexpensive media, and is very easy to handle. A comprehensive panel of plasmids and strategies is available for the expression of recombinant genes and genetic manipulation is nearly as straightforward as for Saccharomyces cerevisiae. As a methylotroph, $P$. pastoris possesses a peculiar methanol utilization pathway relying on some of the strongest and most tightly regulated known promoters that can be used for very-high-level expression of recombinant genes. In addition, P. pastoris can reach very high cell densities (up to $130 \mathrm{~g} / \mathrm{l}$ dry cell weight [5]), and various fermentation processes and formats have been developed in the industry so that up-scaling protein production is easily achievable [10, 11]. Contrary to Escherichia coli, P. pastoris is a eukaryotic microorganism capable of complex post-translational modifications including disulfide isomerization, sulfation, phosphorylation, N-terminal acetylation, C-terminal methylation, myristoylation, farnesylation, and glycosylation (reviewed in [12]), which are often very essential for the proper targeting, biological activity, and stability of the expressed recombinant proteins. Regarding glycosylation, which is central for many membrane proteins [13-15], P. pastoris has been notably shown to graft shorter and more authentic oligosaccharide chains to proteins than S. cerevisiae does [16], and therefore often appeared as a more appropriate system [11]. Finally, ${ }^{15} \mathrm{~N}$ and ${ }^{13} \mathrm{C}$ isotopic labeling of recombinant proteins for nuclear magnetic resonance or spectrometric studies is also achievable with $P$. pastoris, both in a uniform mode using isotopically enriched nitrogen and carbon sources [17] or more selectively using amino acid isotopes and engineered auxotroph strains [18].

This idyllic description has, however, to be tempered with some drawbacks that prevent $P$. pastoris from becoming an ideal expression system. First, a common characteristic for eukaryotic systems that are efficiently overproducing proteins, an overload of the translocation and folding machineries in P. pastoris often creates a stress that triggers the activation of sorting and degradation processes, and results in lowered expression levels and heterogeneity of recombinant proteins [18]. Moreover, if glycosylation processes occur in a fashion acceptable for many 
recombinant proteins, $P$. pastoris is not able to graft the complex carbohydrate motifs that are sometimes critical for the functionality of mammalian proteins. In addition, nonhomogeneous $\mathrm{N}$-glycosylation of recombinant proteins is frequently observed, notably in the case of membrane proteins, leading to some degree of heterogeneity [19-22] that can be detrimental in various applications, including structural studies. Recently, several Pichia strains have been engineered to generate more complex and more homogeneous $\mathrm{N}$-glycosylations (reviewed in [23]). These strains exhibited protein-dependent but promising outcomes, thereby also demonstrating all the potential and possibilities that could be gained from these genetic engineering approaches.

Another characteristic that can have a direct impact on the expression of mammalian membrane proteins is related to the lipidic composition of yeast membranes that varies significantly from that of higher eukaryotes membranes [24]. As membrane proteins do require specific lipids for their proper functions or for their correct folding and stability, these differences may influence both the expression level and functionality of recombinant membrane proteins. This was notably reported in studies where the absence of cholesterol in Pichia membranes was shown to profoundly alter the activity and stability of recombinant membrane proteins [25].

Finally, a secondary but not trivial issue is related to the presence of a significant cell wall surrounding Pichia cells that cannot only hinder the secretion of certain proteins [26], but also represents an obstacle for the preparation of membraneembedded proteins as aggressive disruption methods are needed [27]. Engineered strains with weaker cell walls have been recently developed [26, 28], but none has been reported yet for its use in heterologous expression of membrane proteins and their benefit for a facilitated cell disruption has still to be assayed.

\section{4}

\section{Basics of the $P$. pastoris Expression System}

This section is intended at give a global overview on how the system functions for the heterologous expression of proteins in general, before giving specific details on how it performs in particular for membrane proteins (Section 3.5). Further details on the system as well as additional information concerning secreted and/ or cytosoluble proteins can be found in several excellent and comprehensive reviews that have been published on the topic $[5,6,11,29]$.

\subsection{1}

\section{Methanol Utilization Pathway}

Together with a small set of methylotrophic yeasts from the Pichia, Komagataella, Candida and Ogatae genera, P. pastoris has developed a specific metabolism for the utilization of methanol as sole carbon source. Briefly, methanol enters specialized microbodies, the peroxisomes, where it is oxidized by specific oxidases 
that are encoded by the two genes AOX1 and AOX2 to generate formaldehyde and hydrogen peroxide. While the latter compound is decomposed to water and molecular oxygen by a peroxisomal catalase, formaldehyde leaves the peroxisome to enter both the cytosolic dissimilatory pathway to yield energy and the assimilatory pathway for generation of biomass [30]. The genes encoding the specific enzymes related to this peculiar metabolism are repressed when cells are grown on nonmethanol carbon sources (glucose, glycerol, ethanol, etc.) and are dramatically induced in presence of methanol; alcohol oxidases representing as high as $30 \%$ of the total soluble protein content. These enzymes are thus very tightly regulated and their promoters represent ideal components to be used for recombinant expression - the basis for the development of the $P$. pastoris expression system.

\section{4 .2}

\section{Host Strains and Plasmids}

The principal strains used for recombinant expression derived either from the NRRL Y-11430 (Northern Regional Research Laboratories, Peoria, IL) or the NRRL Y-48124 (Invitrogen expression kit) strains, both being from the K. phaffii type [8]. This limited number of strains is listed in Table 3.1. They mainly differ in their auxotrophic behavior, principally relying on a histidinol dehydrogenase deficiency (his4), allowing, upon transformation, for the positive selection of recombinant expression vectors. Some of them bear additional deficiencies in endogenous proteases (SMD series); others were recently engineered for their capacity in performing "human-like" $N$-glycosylations [23].

Expression vectors (Table 3.2) are built on a classical E. coli/yeast shuttle model

Table 3.1 Most commonly used strains of $P$. pastoris.

\begin{tabular}{|c|c|c|}
\hline Strain & Genotype & Phenotype \\
\hline NRRL $\left.^{a}\right)$ Y-11430 & wild-type & Mut $^{+}$ \\
\hline $\mathrm{X}-33$ & wild-type & $\mathrm{Mut}^{+}$ \\
\hline GS115 & his4 & $\mathrm{Mut}^{+}, \mathrm{His}^{-}$ \\
\hline KM71 & his4, arg4, aox1::ARG4 & $\mathrm{Mut}^{\mathrm{s}}, \mathrm{His}^{-}, \mathrm{Arg}^{+}$ \\
\hline SMD1163 & his4, pep4, prb1 & $\operatorname{Mut}^{+}, \operatorname{His}^{-}, \operatorname{Prot}^{-}\left(\mathrm{A}^{-}, \mathrm{B}^{-}, \mathrm{CarbY}^{-}\right)$ \\
\hline SMD1165 & his4, prb1 & $\mathrm{Mut}^{+}, \mathrm{His}^{-}, \operatorname{Prot}^{-}\left(\mathrm{B}^{-}\right)$ \\
\hline SMD1168 & his4, ura3, pep4::URA3 & Mut $^{+}, \operatorname{His}^{-}, \operatorname{Prot}^{-}\left(\mathrm{A}^{-}, \mathrm{B}^{\mathrm{s}}, \mathrm{CarbY}^{-}\right)$ \\
\hline PichiaPink ${ }^{\circledR}$ Strain 1 & ade2 & $\mathrm{Mut}^{+}, \mathrm{Ade}^{-}$ \\
\hline PichiaPink $^{\circledR}$ Strain 2 & ade2, pep 4 & $\mathrm{Mut}^{+}, \operatorname{Ade}^{-}, \operatorname{Prot}^{-}\left(\mathrm{A}^{-}, \mathrm{B}^{\mathrm{S}}, \mathrm{CarbY}^{-}\right)$ \\
\hline PichiaPink ${ }^{\circledR}$ Strain 3 & ade2, prb1 & $\mathrm{Mut}^{+}, \mathrm{Ade}^{-}, \operatorname{Prot}^{-}\left(\mathrm{B}^{-}\right)$ \\
\hline PichiaPink $^{\circledR}$ Strain 4 & ade2, pep4, prb1 & $\mathrm{Mut}^{+}, \mathrm{Ade}^{-}, \operatorname{Prot}^{-}\left(\mathrm{A}^{-}, \mathrm{B}^{-}, \mathrm{CarbY}^{-}\right)$ \\
\hline
\end{tabular}

a) NRRL, Northern Regional Research Laboratories, Peoria, IL. See text for the explanation of the different elements. 
Table $3.2 \quad$ P. pastoris expression vectors.

\begin{tabular}{|c|c|c|c|c|c|}
\hline Name & $\begin{array}{l}\text { Selection } \\
\text { markers }\end{array}$ & $\begin{array}{l}\text { Phenotype of } \\
\text { transformants }\end{array}$ & Promoter & $\begin{array}{l}\text { Secretion } \\
\text { sequence }\end{array}$ & Added tags \\
\hline pAO815 & HIS4 & $\mathrm{His}^{+}$ & $\mathrm{P}_{A O X 1}$ & none & none \\
\hline pPIC3.5K & HIS4, Kan & $\mathrm{His}^{+}, \mathrm{G} 418^{\mathrm{R}}$ & $\mathrm{P}_{A O X 1}$ & none & none \\
\hline pPIC9K & HIS4, Kan & $\mathrm{His}^{+}, \mathrm{G} 418^{\mathrm{R}}$ & $P_{A O X 1}$ & $\alpha$ factor & none \\
\hline pPICZ A, B, C & Ble & $\mathrm{Zeo}^{\mathrm{R}}$ & $\mathrm{P}_{\text {AOX1 }}$ & none & $\mathrm{c}-\mathrm{Myc} / \mathrm{His}_{6}$ \\
\hline $\mathrm{pPICZ} \alpha \mathrm{A}, \mathrm{B}, \mathrm{C}$ & Ble & $\mathrm{Zeo}^{\mathrm{R}}$ & $P_{A O X 1}$ & $\alpha$ factor & c-Myc/His ${ }_{6}$ \\
\hline pPIC6 A, B, C & $B s d$ & $\mathrm{Bla}^{\mathrm{R}}$ & $\mathrm{P}_{\mathrm{AOX1} 1}$ & none & c-Myc/ $/ \mathrm{His}_{6}$ \\
\hline pHIL-D2 & HIS4 & $\mathrm{His}^{+}$ & $\mathrm{P}_{\mathrm{AOX1}}$ & none & none \\
\hline pHIL-S2 & HIS4 & $\mathrm{His}^{+}$ & $\mathrm{P}_{\text {AOX1 }}$ & PHO1 & none \\
\hline pFLD & Ble & $\mathrm{Zeo}^{\mathrm{R}}$ & $\mathrm{P}_{F L D 1}$ & none & V5 epitope/His 6 \\
\hline pFLD $\alpha$ & Ble & $\mathrm{Zeo}^{\mathrm{R}}$ & $\mathrm{P}_{F L D 1}$ & $\alpha$ factor & V5 epitope/His 6 \\
\hline pGAPZ A, B, C & Ble & $\mathrm{Zeo}^{\mathrm{R}}$ & $P_{G A P}$ & none & $\mathrm{c}-\mathrm{Myc} / \mathrm{His}_{6}$ \\
\hline pGAPZ $\alpha$ A, B, C & Ble & $\mathrm{Zeo}^{\mathrm{R}}$ & $\mathrm{P}_{G A P}$ & $\alpha$ factor & $\mathrm{c}-\mathrm{Myc} / \mathrm{His}_{6}$ \\
\hline pPink-HC & $A D E 2$ & $\mathrm{Ade}^{+}$ & $\mathrm{P}_{\text {AOX1 }}$ & none & none \\
\hline pPink-LC & $A D E 2$ & $\mathrm{Ade}^{+}$ & $P_{A O X 1}$ & none & none \\
\hline pPink $\alpha-H C$ & $A D E 2$ & $\mathrm{Ade}^{+}$ & $\mathrm{P}_{A O X 1}$ & $\alpha$ factor & none \\
\hline \multicolumn{3}{|c|}{$\begin{array}{l}\text { HIS4, P. pastoris auxotrophy marker, } \\
\text { encodes a histidinol dehydrogenase; Kan } \\
\text { gene, confers resistance to kanamycine } \\
\text { (Kan }{ }^{\mathrm{R}} \text {, E. coli) and G418 }\left(\mathrm{G} 418^{\mathrm{R}} \text {, P. pastoris); }\right. \\
\text { Ble, Streptoalloteichus hindustanus ble gene, } \\
\text { confers resistance to zeocin }\left(\mathrm{Zeo}^{\mathrm{R}}\right) ; \text { Bsd gene, } \\
\text { confers resistance to blasticidin }\left(\mathrm{Bla}^{\mathrm{R}}\right) ; \text {; ADE2, } \\
\text { P. pastoris auxotrophy marker, encodes a } \\
\text { phosphoribosylaminoimidazole carboxylase; } \\
\mathrm{P}_{\text {Aoxl }} \text {, promoter sequence of the alcohol }\end{array}$} & \multicolumn{3}{|c|}{$\begin{array}{l}\mathrm{P}_{F L D 1} \text {, promoter sequence of the formaldehyde } \\
\text { dehydrogenase-encoding } F L D 1 \text { gene from } \\
\text { P. pastoris; } \mathrm{P}_{G A P} \text {, promoter sequence of the } \\
\text { glyceraldehyde-3-phosphate dehydrogenase- } \\
\text { encoding GAP gene from } P \text {. pastoris; } \alpha \text { factor, } \\
\text { encodes the native } S \text {. cerevisiae } \alpha \text { factor secretion } \\
\text { signal; PHO1, encodes the native } P \text {. pastoris } \\
\text { acid phosphatase secretion signal; } \mathrm{V} 5 \text { epitope, } \\
\text { GKPIPNPLLGLDST peptide; } \text {-Myc, C-terminal } \\
\text { myc epitope, EQKLISEEDL. }\end{array}$} \\
\hline
\end{tabular}

with components required for $E$. coli amplification (classically one origin of replication and one antibiotic selection marker) and specific elements for heterologous gene expression in $P$. pastoris. These typically include selectable auxotrophy markers (HIS4, ADE2) and/or antibiotic resistance bacterial genes (bla, zeo, and $k a n)$, a range of promoter and terminator sequences, a multiple cloning cassette, and supplementary signal sequences and other fusion sequences that can be added to improve the secretion and detection of the expressed proteins.

Among the panel of constitutive and inducible promoters that have been introduced in expression vectors (listed in [31]), $\mathrm{P}_{A O X 1}$ is by far the most widely used as it is the most strongly induced in the presence of methanol. Moreover, an original $\mathrm{P}_{\text {AOX1 } 1}$ synthetic promoter library was developed in a recent study that demonstrated enhanced $\mathrm{P}_{A 0 X 1}$ variants could reach higher expression levels of a tested recombinant Green Fluorescent Protein (GFP) [31].

A comprehensive set of vectors and strains is commercially available from Invitrogen, each of them being accessible either individually or included in expression kits. 


\section{4 .3}

\section{Transformation and Clone Selection Strategies}

As for many other yeasts, transformation of $P$. pastoris is rather straightforward. Several robust methods are available, either based on chemically competent (spheroplasts, PEG1000, $\mathrm{LiCl}$ ) or electrocompetent cells, thus being accessible to a large majority of operators in standard labs. Moreover, these protocols are well described and can be easily found on numerous websites (convenient Pichia manuals can be downloaded from www.invitrogen.com).

Except for a limited set of autoreplicative plasmids that are not yet frequently employed [32-35], most of the transforming expression vectors are designed to be maintained as integrative elements in the genome of $P$. pastoris. This is generally achieved through recombination events between linearized sequences borne by the plasmids (typically HIS4 or $\mathrm{P}_{A O X 1}$ ) and their homologous sequence counterparts present on the genome, leading to the targeted insertion of the expression vectors. Moreover, such plasmid insertions frequently occur in tandem in yeasts and thus lead to the multiple integration of the genes of interest with a correlated impact on their subsequent expression levels.

Alternatively, integration can be obtained by a gene replacement strategy. In this case, a double recombination event must be realized between the AOX1 promoter and terminator sequences present on the transforming DNA (containing the gene of interest and a selection marker) and the corresponding homologous sequences present on $P$. pastoris genome. This double recombination event ends up with the replacement of the $A O X 1$ gene by the construct of interest.

The phenotype of the resulting transformants then depends not only on the selection marker present on the chosen vector (auxotrophy and/or antibiotic resistance), but also on the selected integration strategy (plasmid insertion versus gene replacement) that dictates their methanol utilization behavior. Indeed, while a plasmid insertion does not affect the methanol utilization ability of the transformed strain ( $\mathrm{Mut}^{+}$, methanol utilization plus phenotype), the gene replacement of $A O X 1$ leads to a $\mathrm{Mut}^{\mathrm{S}}$ (methanol utilization slow) phenotype. In several cases, these differences in methanol utilization have been reported as an important parameter to consider for enhancing the performance of recombinant protein expression [36].

\section{4 .4}

\section{Expression Conditions and Culturing Formats}

Once transformants have been obtained, the next step usually consists in screening for the clones and conditions exhibiting the best expression levels of the recombinant protein. For expression strategies based on $\mathrm{P}_{\mathrm{AOX1}}$-dependent vectors, this is practically achieved by growing the cells in repressive media to an appropriate cell density and growth phase, before starting the production phase by transferring the cells to a methanol-containing induction media. For clones and expression condition screenings, small-scale culturing procedures most often rely on shaken baffled-flasks or on tubes of smaller volumes provided an appropriate aeration is 
maintained. Several parameters are then usually adjusted for an optimal expression, such as the duration and the temperature of the induction phase, as well as the media formulation including the methanol concentration and the use of additive compounds.

For the production of large amounts of heterologous proteins, shake-flask culture is usually not recommended due to the limitations of volume, oxygen transfer, substrate addition, and an inability to monitor these factors efficiently. The use of bioreactors is therefore preferred, since all of these parameters can be monitored and controlled simultaneously, allowing more efficient production of the desired heterologous protein. Accordingly, a number of robust fermentation processes including fed-batch techniques and continuous culturing procedures have been developed and are routinely employed. Detailed descriptions of these methods with their benefits and limitations can be found in several excellent and comprehensive reviews that we recommend $[6,10,11,37]$.

\section{5}

\section{Successful Large-Scale Expression of Membrane Proteins Using P. pastoris}

\subsection{1}

\section{P. pastoris for Membrane Protein expression}

The first use of $P$. pastoris as a host for the expression of an integral membrane protein was reported in 1995 when Helmut Reilander and his colleagues successfully expressed a member of the G-protein-coupled receptor (GPCR) family - the mouse serotonin receptor $5-\mathrm{HT}_{5 \mathrm{~A}}$ [38]. Few additional membrane proteins were then assayed in the following years before the system became more and more popular in the 2000s: a thorough survey we conducted on the last decade of published results revealed 100 references encompassing more than 150 different membrane proteins expressed in P. pastoris (Table 3.3). In this list where only integral membrane proteins were considered (soluble domains of membrane proteins as well as membrane-anchored proteins were excluded), all classes of eukaryotic membrane proteins are equally represented. This includes monotopic receptors and enzymes, several aquaporins and ion channels, many members of the GPCR family, as well as large polytopic transporters bearing up to 17 putative transmembrane domains. This survey also highlights the great potential of $P$. pastoris for coexpression approaches, including studies on two membrane subunits of multimeric protein complexes, two interacting membrane protein partners, as well as a membrane protein and a cytosolic partner, in strategies where the coexpressed genes are either borne on a same vector or on two distinct vectors. Successful coexpression was actually recorded for the $\alpha$ and $\beta$ subunits of $\mathrm{Na} / \mathrm{K}$ ATPase [39-42], and for $\alpha / \beta$ and phospholemman (a membrane modulator of the enzyme) [43]. Similarly, coexpression strategies were also reported for $\mathrm{K}_{\mathrm{v}} 1.2$, a membrane subunit, and $\mathrm{K}_{\mathrm{v}} \beta 2$, a cytosoluble partner, of the rat voltage-dependent $\mathrm{K}^{+}$channel [44-46]. 
$82 \mid 3$ Expression Systems: Pichia pastoris

Table 3.3 Recombinant membrane proteins produced using the $P$. pastoris expression system.

\begin{tabular}{|c|c|c|c|c|}
\hline Protein name & Organism & $\mathrm{kDa}$ & $\begin{array}{l}\text { Transmembrane } \\
\text { domains }\end{array}$ & Strains \\
\hline \multicolumn{5}{|l|}{ Transporters } \\
\hline P-glycoprotein MDR3 & mouse & 140 & 12 & GS115 \\
\hline $\begin{array}{l}\text { P-glycoproteins MDR3 (S430T, } \\
\text { S1073T) }\end{array}$ & mouse & 140 & 12 & GS115 \\
\hline $\begin{array}{l}\text { Multidrug resistance protein } \\
\text { MRP1 }\end{array}$ & human & 165 & 17 & GS115, KM71 \\
\hline Phosphate transporter MtPT1 & Medicago truncatula & 45 & ND & GS115 \\
\hline $\begin{array}{l}\text { Intestinal peptide transporter } \\
\text { hPEPT1 }\end{array}$ & human & 71 & ND & GS115 \\
\hline $\begin{array}{l}\text { P-glycoproteins MDR1, MDR3 } \\
\text { (unglycosylated) }\end{array}$ & human, mouse & 140 & 12 & GS115 \\
\hline P-glycoprotein MDR1 (Cys-less) & human & 140 & 12 & GS115 \\
\hline $\begin{array}{l}\text { Antimalarial drug resistance } \\
\text { protein Pfcrt (codon-optimized) }\end{array}$ & $\begin{array}{l}\text { Plasmodium } \\
\text { falciparum }\end{array}$ & 57 & 10 & KM71, GS115 \\
\hline P-glycoprotein MDR3 & mouse & 140 & 12 & GS115 \\
\hline Serotonin transporter rSERT & rat & 50 & 12 & $\begin{array}{l}\text { GS115, } \\
\text { SMD1168 }\end{array}$ \\
\hline $\begin{array}{l}\text { Breast cancer resistance protein } \\
\text { BCRP }\end{array}$ & human & 62 & 6 & KM71 \\
\hline $\begin{array}{l}\text { Sodium/glucose cotransporter } \\
\text { hSGLT1 }\end{array}$ & human & 55 & 9 & GS115 \\
\hline Copper transporter hCTR1 & human & 23 & 3 & SMD1163 \\
\hline $\begin{array}{l}\text { Low-affinity cation transporter } \\
\text { LCT1 }\end{array}$ & wheat & ND & ND & GS115 \\
\hline $\begin{array}{l}\text { Chloroquine resistance } \\
\text { transporter PfCRT } \\
\text { (codon-optimized) }\end{array}$ & $\begin{array}{l}\text { Plasmodium } \\
\text { falciparum }\end{array}$ & 45 & 10 & KM71 \\
\hline P-glycoprotein MDR3 (Cys-less) & mouse & 140 & 12 & GS115 \\
\hline $\begin{array}{l}\text { Multidrug resistance protein } \\
\text { PfMDR1 (codon-optimized) }\end{array}$ & $\begin{array}{l}\text { Plasmodium } \\
\text { falciparum }\end{array}$ & 161 & 12 & KM71, X-33 \\
\hline $\begin{array}{l}16 \text { ABC transporters: ABCC } 3 \text {, } \\
\text { ABC A1, A4, B1, C10, C11, C12, } \\
\text { G5, G8, B7, B6, D1, E1, F1, G1, } \\
\text { G4 }\end{array}$ & human & 176 & 6,12 & KM71 \\
\hline Glucose transporter NlHT1 & Nilaparvata lugens & 40 & 12 & $X-33$ \\
\hline
\end{tabular}


3.5 Successful Large-Scale Expression of Membrane Proteins Using P. pastoris $\mid 83$

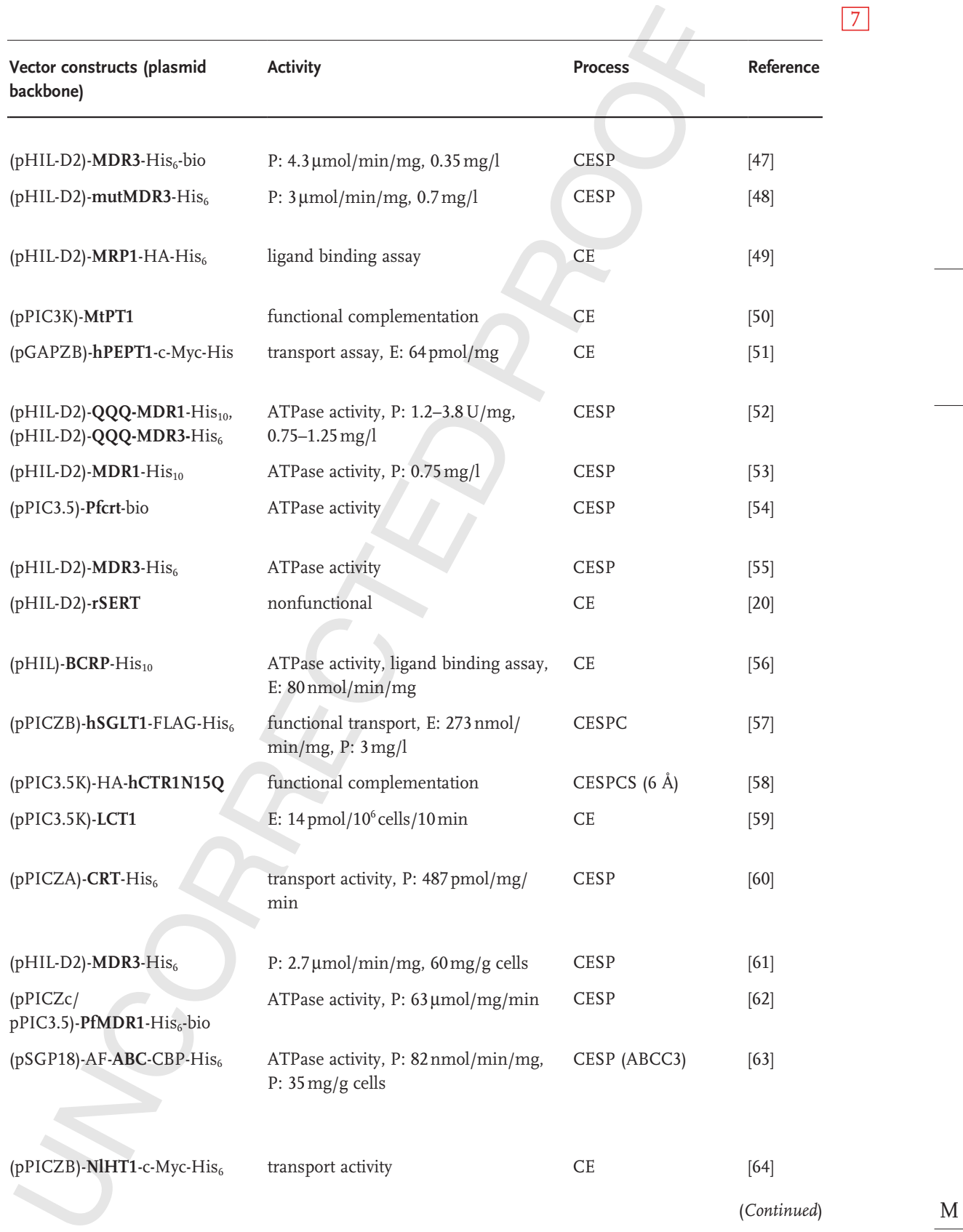


Table 3.3 (Continued)

\begin{tabular}{|c|c|c|c|c|}
\hline Protein name & Organism & $\mathrm{kDa}$ & $\begin{array}{l}\text { Transmembrane } \\
\text { domains }\end{array}$ & Strains \\
\hline $\begin{array}{l}\text { Vesicular glutamate transporter } \\
\text { VGLUT1 }\end{array}$ & rat & 61 & 12 & $\mathrm{X}-33$ \\
\hline $\begin{array}{l}\text { Glucose transporters GLUT1 and } \\
\text { GLUT4 }\end{array}$ & human, rat & 42,46 & 12 & $\mathrm{X}-33$ \\
\hline P-glycoprotein Pgp & mouse & ND & 12 & GS115 \\
\hline $\begin{array}{l}\text { Formate-nitrite transporter } \\
\text { AnNitA }\end{array}$ & Aspergillus nidulans & 31 & 6,8 & GS115 \\
\hline \multicolumn{5}{|l|}{ Water channel proteins } \\
\hline Aquaporin PM28A & spinach & 32 & 6 & $\mathrm{X}-33$ \\
\hline Aquaporin SoPIP2;1 & spinach & 32 & 6 & ND \\
\hline Aquaporin PvTIP3;1 & plant & 25 & 6 & KM71 \\
\hline Aquaporin SoPIP2.1 & spinach & 32 & 6 & $X-33$ \\
\hline Aquaporin AQP6 & rat & 29 & 6 & $\begin{array}{l}\text { X-33, GS115, } \\
\text { KM71 }\end{array}$ \\
\hline Aquaporin hAQP1 & human & 35 & 6 & $X-33$ \\
\hline $\begin{array}{l}\text { Aquaglyceroporin PfAQP } \\
\text { (codon-optimized) }\end{array}$ & $\begin{array}{l}\text { Plasmodium } \\
\text { falciparum }\end{array}$ & 30 & 6 & $X-33$ \\
\hline Aquaporin HsAQP5 & human & ND & 6 & ND \\
\hline Aquaporin AtPIP2;1 & Arabidopsis thaliana & 55 & 6 & $\mathrm{X}-33$ \\
\hline Aquaporins TgPIP2;1, TgPIP2;2 & Tulipa gesneriana & 31 & 6 & KM71 \\
\hline Aquaporin Aqy1 & Pichia pastoris & ND & 6 & GS115 aqy 1 \\
\hline Aquaporin hAQP4 & human & ND & 6 & $\mathrm{X}-33$ \\
\hline $\begin{array}{l}13 \text { Aquaporins (hAQP0 to } \\
\text { hAQP12) }\end{array}$ & human & 30 & 6 & $X-33$ \\
\hline Ion channel proteins & & & & \\
\hline $\begin{array}{l}\text { Voltage-sensitive } \mathrm{K}^{+} \text {channel } \\
\mathrm{K}_{\mathrm{v}} 1.2 / \beta 2 \text { (coexpression) }\end{array}$ & rat & $58 / 40$ & 6 & SMD1163 \\
\hline $\begin{array}{l}\text { Voltage-dependent } \mathrm{K}^{+} \text {channel } \\
\mathrm{K}_{\mathrm{v}} 1.2 / \beta 2 \text { (coexpression) }\end{array}$ & rat & ND & 6 & SMD1163 \\
\hline Calcium-activated $\mathrm{K}^{+}$channel SK2 & mammalian & 64 & 6 & SMD1163 \\
\hline $\begin{array}{l}\text { Chimeric } \mathrm{K}^{+} \text {channel } \mathrm{K}_{\mathrm{v}} 1.2 / \\
\mathrm{K}_{\mathrm{v}} 2.1 / \beta 2.1 \text { (coexpression) }\end{array}$ & rat & ND & 6 & SMD1163 \\
\hline Inward-rectifier $\mathrm{K}^{+}$channel $\mathrm{K}_{\mathrm{ir}} 2.2$ & chicken & ND & 6 & SMD1163 \\
\hline
\end{tabular}


3.5 Successful Large-Scale Expression of Membrane Proteins Using P. pastoris $\mid 85$

\begin{tabular}{|c|c|c|c|}
\hline $\begin{array}{l}\text { Vector constructs (plasmid } \\
\text { backbone) }\end{array}$ & Activity & Process & Reference \\
\hline (pGAPZB)-c-Myc-His-VGLUT1 & $\mathrm{P}: 1 \mathrm{mg} / \mathrm{l}$ & CESP & {$[65]$} \\
\hline (pPICZB)-GLUT-His 8 & transport activity, P: $13.1 \mathrm{mg} / \mathrm{g}$ cells & CESPC & {$[66]$} \\
\hline (pHIL-D2)-QQQ-Pgp-His ${ }_{6}$ & ATPase activity & CESPCS $(3.8 \AA)$ & [67] \\
\hline (pPICZA)- $-\mathrm{His}_{6}$-AnNitA & ND & CESP & {$[68]$} \\
\hline (pPICZB)-PM28A-c-Myc-His 6 & $\mathrm{P}: 25 \mathrm{mg} / \mathrm{l}$ & CESP & [69] \\
\hline (ND)-SoPIP2;1 & water channel activity & CESPCS $(5 \AA)$ & {$[70]$} \\
\hline (pPICZ)-PvTIP3;1-gly3-His 6 & water channel activity & $\mathrm{CE}$ & {$[71]$} \\
\hline (pPICZB)-SoPIP2.1 $\pm \mathrm{His}_{6}$ & $\mathrm{P}: 25 \mathrm{mg} / \mathrm{l}$ & CESPCS $(2.1,3.9 \AA)$ & [72] \\
\hline (pPICHOLi/pPICZ)-AQP6-His ${ }_{6}$ & $\mathrm{E}: 7 \mathrm{pmol} / \mathrm{mg}$ & $\mathrm{CE}$ & [73] \\
\hline (pPICZB)-hAQP1-c-Myc-His ${ }_{6}$ & water channel activity, P: $90 \mathrm{mg} / \mathrm{l}$ & CESPC & [74] \\
\hline (pPICZB)-PfAQP-c-Myc-His ${ }_{6}$ & $\mathrm{P}: 18 \mathrm{mg} / \mathrm{l}$ & CESPC & {$[75]$} \\
\hline (pPICZB)-HsAQP5 & water channel activity & CESPCS $(2 \AA)$ & [76] \\
\hline (pPICZB)-WT/mutAtPIP2;1 & water channel activity, P: $65 \mu \mathrm{g} / \mathrm{l}$ & CESP & {$[77]$} \\
\hline (pPICZB)-TgPIP2-gly3-His 6 & water channel activity & $\mathrm{CE}$ & [78] \\
\hline (pPICZaB)- $\Delta$ N36Aqy1- $\mathrm{His}_{6}$ & water channel activity & CESPCS $(1.5 \AA)$ & [79] \\
\hline (pPICZ)-His ${ }_{8}$-FLAG-hAQP4 & water channel activity & CESPCS $(1.8 \AA)$ & {$[80]$} \\
\hline (pPICZB)-hAQP-His ${ }_{6}$ & water channel activity & $\mathrm{CE}$ & {$[81]$} \\
\hline $\begin{array}{l}(\mathrm{pPIC} 3.5 \mathrm{~K})-\mathrm{His}_{8}-\mathrm{K}_{\mathrm{v}} 1.2 \\
(\mathrm{pPICZC})-\text { strepII-K } \\
\mathbf{p} \boldsymbol{\beta} 2\end{array}$ & $\begin{array}{l}\text { E: } 98 \mathrm{pmol} / \mathrm{mg}, \mathrm{P}: 26 \mathrm{mg}, 3.3 \mathrm{nmol} / \\
\mathrm{mg}\end{array}$ & CESPCS $(2.1 \mathrm{~nm})$ & [44] \\
\hline (pPICZC)-His ${ }_{8}-\mathrm{K}_{\mathrm{v}} 1.2-\beta 2$ & $\mathrm{P}: 10 \mathrm{mg} / \mathrm{ml}$ & CESPCS $(2.9 \AA)$ & {$[45]$} \\
\hline (pPIC3.5K)-strepII-His-SK2 & E: $0.1 \mathrm{pmol} / \mathrm{mg}$ & CES & {$[82]$} \\
\hline $\begin{array}{l}(\mathrm{pPICZC})-\mathrm{His}_{10}-\mathrm{K}_{\mathrm{v}} 1.2 / \\
\mathrm{K}_{\mathrm{v}} 2.1 / \boldsymbol{\beta} 2.1\end{array}$ & channel activation & CESPCS $(2.4 \AA)$ & {$[46]$} \\
\hline (pPICZB)-K $\mathrm{K}_{\mathrm{ir}} 2.2-\mathrm{GFP}-1 \mathrm{D} 4$ & channel activation, $\mathrm{P}: 8 \mathrm{mg} / \mathrm{ml}$ & CESPCS $(3.1 \AA)$ & {$[83]$} \\
\hline
\end{tabular}

(Continued) 
$86 \mid 3$ Expression Systems: Pichia pastoris

Table 3.3 (Continued)

\begin{tabular}{|c|c|c|c|c|}
\hline Protein name & Organism & $\mathrm{kDa}$ & $\begin{array}{l}\text { Transmembrane } \\
\text { domains }\end{array}$ & Strains \\
\hline \multicolumn{5}{|l|}{ GPCRs } \\
\hline Endothelin receptor B ETB & human & 55 & 7 & SMD1163 \\
\hline Endothelin receptor B ETB & human & 55 & 7 & SMD1163 \\
\hline Cannabinoid receptor CB2 & human & 51 & 7 & $\mathrm{X}-33$ \\
\hline Mu-opioid receptor HuMOR & human & 74 & 7 & $\begin{array}{l}\text { GS115, } \\
\text { SMD1163, } \\
\text { SMD1168, X-33 }\end{array}$ \\
\hline Dopamine receptor $\mathrm{D}_{2 \mathrm{~s}}$ & human & 40 & 7 & SMD1163 \\
\hline Dopamine receptor $\mathrm{D}_{2 \mathrm{~s}}$ & human & 51 & 7 & SMD1163 \\
\hline Receptor smoothened hSmo & human & 80 & 7 & GS115 \\
\hline Cannabinoid receptor CB1 & human & 75 & 7 & $\mathrm{X}-33$ \\
\hline Mu-opioid receptor HuMOR & human & $45 / 66$ & 7 & SMD1163 \\
\hline $\begin{array}{l}20 \text { GPCRs: ADA1B, ADA2B, } \\
\text { ACM1, ACM2, HRH2, OPRK, } \text { 5HT }_{1 \mathrm{D}}, 5 \mathrm{HT}_{1 \mathrm{~B}}, 5 \mathrm{HT}_{1 \mathrm{~A}}, \mathrm{DRD} 2 \text {, } \\
\mathrm{NK}_{1 \mathrm{R}}, \mathrm{NK} 2 \mathrm{R}, \mathrm{NK} 3 \mathrm{R}, \mathrm{NPY} 1 \mathrm{R}, \\
\mathrm{AA}_{2 \mathrm{~A}} \mathrm{R}\end{array}$ & $\begin{array}{l}\text { human, pig, mouse, } \\
\text { rat }\end{array}$ & ND & 7 & SMD1163 \\
\hline Adenosine $A_{2 A}$ receptor $h A_{2 A} R$ & human & 34 & 7 & SMD1163 \\
\hline $\begin{array}{l}\beta_{2} \text {-Adrenergic receptor } \beta_{2} \mathrm{AR} \\
\text { (codon-optimized) }\end{array}$ & human & 45 & 7 & SMD1168 \\
\hline 100 GPCRs & $\begin{array}{l}\text { human, pig, mouse, } \\
\text { rat, bovine, yeast }\end{array}$ & $36-126$ & 7 & SMD1163 \\
\hline EDG-1 receptors & human & 69 & 7 & SMD1168 \\
\hline Bradykinin B2 receptor B2R & human & 68 & 7 & GS115 \\
\hline Bradykinin B2 receptor B2R & human & 55 & 7 & SMD1163 \\
\hline
\end{tabular}




\begin{tabular}{|c|c|c|c|}
\hline $\begin{array}{l}\text { Vector constructs (plasmid } \\
\text { backbone) }\end{array}$ & Activity & Process & Reference \\
\hline $\begin{array}{l}\text { (pPIC9K)-AF-FLAG- } \\
\text { ETB/ } \Delta \text { GPETB-bio }\end{array}$ & E: $35-60 \mathrm{pmol} / \mathrm{mg}$ & CE & [84] \\
\hline $\begin{array}{l}\text { (pPIC9K)-AF-FLAG- } \Delta \text { GPETB- } \\
\text { bio/GFP/His }{ }_{10} \text {; } \\
\text { (pPIC9K)-AF-FLAG-His }{ }_{10^{-}} \\
\Delta \text { GPETB-bio }\end{array}$ & E: $7-60 \mathrm{pmol} / \mathrm{mg}$ & CESP & [85] \\
\hline (pPICZa)-AF-CB2-c-Myc-His ${ }_{6}$ & $\mathrm{E}: 2.6 \mathrm{pmol} / \mathrm{mg}$ & CESP & {$[86]$} \\
\hline $\begin{array}{l}\text { (pPICZaA)-AF-GFP-HuMOR-c- } \\
\text { Myc-His }_{6}\end{array}$ & $\mathrm{E}: 1 \mathrm{pmol} / \mathrm{mg}$ & $\mathrm{CE}$ & {$[87,88]$} \\
\hline (pPIC9K)-AF-FLAG \pm His $_{6}-\mathrm{D}_{2 \mathrm{~S}}$ & $\mathrm{P}: 10 \mathrm{pmol} / \mathrm{mg}$ & CESP & [89] \\
\hline $\begin{array}{l}\text { (pPIC9K)-AF-FLAG } \pm \text { His }_{6}-\mathrm{D}_{2 \mathrm{~S}} \\
\text { (pPIC9K)-AF-FLAG-D } \\
\text { bio }-\mathrm{His}_{10} /\end{array}$ & $\mathrm{E}: 37-80 \mathrm{pmol} / \mathrm{mg}$ & CES & {$[90]$} \\
\hline $\begin{array}{l}\text { (pAO815)-hSmo-CBD-strep- } \\
\text { HA-His }_{6}\end{array}$ & ND & CESP & {$[91]$} \\
\hline $\begin{array}{l}\text { (pPICZa)-AF-FLAG-CB1-c-Myc- } \\
\text { His }_{6}\end{array}$ & $\mathrm{E}: 3.6 \mathrm{pmol} / \mathrm{mg}$ & CESP & [92] \\
\hline $\begin{array}{l}(\mathrm{pPICZ}) \pm \\
\text { GFP-HuMOR-c-Myc-His } \\
\end{array}$ & $\mathrm{E}: 0.45 \mathrm{pmol} / \mathrm{mg}$ & CESP & [93] \\
\hline $\begin{array}{l}\text { (pPIC9K)-AF-FLAG-His }{ }_{10^{-}} \\
\text {GPCR-bio }\end{array}$ & $\mathrm{E}: 0.3-165 \mathrm{pmol} / \mathrm{mg}$ & $\mathrm{CE}$ & [94] \\
\hline $\begin{array}{l}(\mathrm{pPICZaA})-A F-F L A G-\mathrm{His}_{10^{-}} \\
\mathbf{h A}_{2 \mathrm{~A}} \mathbf{R}\end{array}$ & $\mathrm{P}: 18 \mathrm{nmol} / \mathrm{mg}$ & CESP & {$[95]$} \\
\hline (pPIC9K)-AF-His ${ }_{6}-\beta_{2} \mathrm{AR}$ & $\mathrm{P}: 11 \mathrm{nmol} / \mathrm{mg}$ & CESP & [96] \\
\hline $\begin{array}{l}\text { (pPIC9K)-AF-FLAG-His }{ }_{10} \\
\text { GPCR-bio }\end{array}$ & E: $0.1-180 \mathrm{pmol} / \mathrm{mg}$ & $\mathrm{CE}$ & [97] \\
\hline (pPIC9K)-AF-EDG-1-GFP & $\mathrm{E}: 8.2 \mathrm{pmol} / \mathrm{mg}$ & CES & [98] \\
\hline (pPIC9K)-AF-B2R-GFP & ND & CES & [99] \\
\hline $\begin{array}{l}\text { (pPIC9K)-AF-FLAG-His }{ }_{10} \text {-B2R- } \\
\text { bio }\end{array}$ & $\mathrm{E}: 3.5 \mathrm{pmol} / \mathrm{mg}$ & $\mathrm{CE}$ & {$[100]$} \\
\hline
\end{tabular}

(pPIC9K)-AF-FLAG

(pPIC9K)-AF-FLAG- $\triangle$ GPETB-

bio/GFP/His ${ }_{10}$;

(pPIC9K)-AF-FLAG-His ${ }_{10^{-}}$

(pPICZa)-AF-CB2-c-Myc-His 6

(pPICZaA)-AF-GFP-HuMOR-c-

Myc-His $_{6}$

(pPIC9K)-AF-FLAG \pm His $_{6}-D_{2 S}$,
(pPIC9K)-AF-FLAG-D ${ }_{25}-H^{-} i_{10} /$
bio

(pAO815)-hSmo-CBD-strep- ND

(pPICZa)-AF-FLAG-CB1-c-Myc$\mathrm{His}_{6}$

(pPICZ) \pm

E: $0.45 \mathrm{pmol} / \mathrm{mg}$

E: $0.3-165 \mathrm{pmol} / \mathrm{mg}$

(Continued) 


\begin{tabular}{|c|c|c|c|c|}
\hline Protein name & Organism & $\mathrm{kDa}$ & $\begin{array}{l}\text { Transmembrane } \\
\text { domains }\end{array}$ & Strains \\
\hline Neuromedin $\mathrm{U}$ receptor NmU2R & human & 60 & 7 & SMD1163 \\
\hline Cannabinoid receptor CB2 & human & 42 & 7 & $\mathrm{X}-33$ \\
\hline $\begin{array}{l}12 \text { GPCRs: CNR2, NK1R, NK3R, } \\
\text { ADA1B, ADA2B, ADA2C, D2DR, } \\
\text { OPRK, OPRD, P2RY1, HRH1, } \\
\text { PAR1 }\end{array}$ & human, rat & $40-50$ & 7 & SMD1163 \\
\hline $\begin{array}{l}\text { Mu-opioid receptor }(\Delta \mathrm{N} 64) \\
\Delta \mathrm{N} 64-\mathrm{HuMOR}\end{array}$ & human & 38 & 7 & SMD1163 \\
\hline $\begin{array}{l}\beta \text {-Adrenergic receptors } \beta_{1} \mathrm{AR}, \\
\beta_{2} \mathrm{AR}, \beta_{3} \mathrm{AR}\end{array}$ & human & 66 & 7 & SMD1163 \\
\hline $\begin{array}{l}25 \text { nonglycosylated GPCRs: } \\
\text { CNR1, AGTR2, HTR1B, } \\
\text { ADORA2A, DRD1, DRD2, DRD4, } \\
\text { DRD5, OPRK, CHRM2, PTGER1, } \\
\text { PTGER2, PTGER3, PTGER4, } \\
\text { TBXRA2, TACR1, TACR2, } \\
\text { TACR3, NTSR1, ADRB2, HRH4 }\end{array}$ & human, mouse & ND & 7 & SMD1163 \\
\hline Leukotriene $\mathrm{B}_{4}$ receptor BLT1 & guinea pig & 100 & 7 & GS115 \\
\hline Enzymes & & $p$ & & \\
\hline $\begin{array}{l}11 \beta \text {-OH steroid dehydrogenase } \\
11 \beta \text {-HSD1 }\end{array}$ & human & 29 & ND & GS115 \\
\hline Monoamine oxidase B MAOB & human & 60 & 1 & KM71, GS115 \\
\hline Monoamine oxidase B MAOB & human & 60 & 1 & KM71, GS115 \\
\hline Monoamine oxidase A MAOA & human & 60 & 1 & KM71 \\
\hline $\begin{array}{l}\text { 11ß-OH steroid dehydrogenases } \\
11 \beta \text {-HSD1 }\end{array}$ & human, rat & 31 & ND & GS115, X-33 \\
\hline $\begin{array}{l}\text { Isatin-bound monoamine oxidase } \\
\text { B MAOB }\end{array}$ & human & 60 & 1 & KM71, GS115 \\
\hline $\begin{array}{l}\mathrm{Na} / \mathrm{K} \text {-ATPase }\left(\alpha_{1}, \beta_{1}\right) \\
\text { (coexpression) }\end{array}$ & pig & $112 / 47$ & 10,1 & SMD1165 \\
\hline Oxidosqualene cyclase hOSC & human & 80 & 1 & GS115 \\
\hline $\begin{array}{l}\mathrm{Na} / \mathrm{K}-\mathrm{ATPase}(\alpha, \beta) \\
\text { (coexpression) }\end{array}$ & pig & ND & 10,1 & SMD1165 \\
\hline
\end{tabular}


3.5 Successful Large-Scale Expression of Membrane Proteins Using P. pastoris 89

\begin{tabular}{|c|c|c|c|}
\hline $\begin{array}{l}\text { Vector constructs (plasmid } \\
\text { backbone) }\end{array}$ & Activity & Process & Reference \\
\hline $\begin{array}{l}\text { (pPIC9K)-AF-FLAG-His } 10^{-} \\
\text {NmU2R-bio }\end{array}$ & $\mathrm{E}: 6 \mathrm{pmol} / \mathrm{mg}$ & $\mathrm{CE}$ & {$[21]$} \\
\hline $\begin{array}{l}\text { (pPICZa)-AF-FLAG-CB2-c-Myc- } \\
\text { His }_{6} ;(\text { pPICZa)-AF-FLAG-CB2- } \\
\text { His }_{6} / \text { His }_{10}\end{array}$ & ligand binding assay & CESP & {$[101]$} \\
\hline $\begin{array}{l}\text { (pPIC9K)-AF-FLAG-His } 10^{-} \\
\text {GPCR-bio }\end{array}$ & $\begin{array}{l}\text { ligand binding assay, } P \text { : up to } \\
0.9 \mathrm{mg} / \mathrm{l}\end{array}$ & CESP & {$[102]$} \\
\hline $\begin{array}{l}(\mathrm{pPICZB}) \pm \mathrm{AF} \pm \\
\text { GFP- } \Delta \text { N64-HuMOR-c-Myc-His } \\
\end{array}$ & $\mathrm{P}: 5 \mathrm{mg} / \mathrm{l}$ & CESP & {$[103]$} \\
\hline $\begin{array}{l}\text { (pPICZ)-AF-GFP- } \beta \text { AR-c-Myc- } \\
\text { His }_{6}\end{array}$ & ND & CESP & {$[104]$} \\
\hline $\begin{array}{l}\text { (pPIC9K)-AF-FLAG-GPCR- } \\
\text { His }_{10}\end{array}$ & E: $0-75.4 \mathrm{pmol} / \mathrm{mg}$ & $\mathrm{CE}$ & {$[22]$} \\
\hline (pPIC3.5K)-AF-FLAG-BLT1 & $\mathrm{E}: 50 \mathrm{pmol} / \mathrm{mg}, \mathrm{P}: 0.4 \mathrm{mg} / \mathrm{l}$ & CESP & {$[105]$} \\
\hline (pPIC3.5K)-11ß-HSD1 & enzyme activity & $\mathrm{CE}$ & {$[106]$} \\
\hline (pPIC3.5K)-MAOB & oxidase activity P: $100 \mathrm{mg} / \mathrm{l}$ & CESP & {$[107]$} \\
\hline (pPIC3.5K)-MAOB & ND & CESPCS $(3 \AA)$ & {$[108]$} \\
\hline (pPIC3.5K)-MAOA & P: $115 \mathrm{mg} / \mathrm{l}$ & CESP & [109] \\
\hline $\begin{array}{l}\text { (pPIC3.5K/ } \\
\text { pPICZB)-His } 6 \text {-11 } \beta-H S D 1\end{array}$ & $\begin{array}{l}\text { dehydrogenase activity, S: } 713 \text { pmol/ } \\
\mathrm{min} / \mathrm{mg}\end{array}$ & CESP & {$[110]$} \\
\hline (pPIC3.5K)-MAOB & ND & CESPCS $(1.7 \AA)$ & {$[111]$} \\
\hline$\left(\right.$ pHIL-D2)- $\boldsymbol{\alpha}_{1} / \boldsymbol{\beta}_{1}$ & E: $30-50 \mathrm{pmol} / \mathrm{mg}$ & $\mathrm{CE}$ & [39] \\
\hline (pPICZB)-hOSC-c-Myc- $-\mathrm{His}_{6}$ & $\mathrm{IC}_{50}$ values, $\mathrm{P}: 105 \mathrm{mg} / \mathrm{l}$ & CESPC & {$[112]$} \\
\hline (pHIL-D2)- $\alpha /$ His $_{10}-\beta$ & $\mathrm{E}: 30 \mathrm{pmol} / \mathrm{mg}, 1 \mathrm{~g} / 31$ & CESP & {$[40]$} \\
\hline
\end{tabular}


$90 \mid 3$ Expression Systems: Pichia pastoris

Table 3.3 (Continued)

\begin{tabular}{|c|c|c|c|c|}
\hline Protein name & Organism & $\mathrm{kDa}$ & $\begin{array}{l}\text { Transmembrane } \\
\text { domains }\end{array}$ & Strains \\
\hline $\begin{array}{l}\text { Clorgyline-bound monoamine } \\
\text { oxidase A MAOA }\end{array}$ & human & 60 & 1 & KM71 \\
\hline $\begin{array}{l}\text { Cytochrome P450 2D6 } \\
\text { monooxygenase CYP2D6/ } \\
\text { NADPH P450 oxidoreductase } \\
\text { CPR (coexpression) }\end{array}$ & human & $56 / 77$ & 1,1 & $\mathrm{X}-33$ \\
\hline Adrenal cytochrome $b_{561}$ Cytb561 & bovine & 28 & 5,6 & GS115 \\
\hline Cytochrome P450 PcCYP1f & $\begin{array}{l}\text { Phanerochaete } \\
\text { chrysosporium }\end{array}$ & 60 & ND & KM71 \\
\hline $\begin{array}{l}\text { Phospholemman (PLM)/ } \\
\text { Na/K-ATPase }\left(\alpha_{1}, \beta_{1}\right) \\
\text { (coexpression) }\end{array}$ & $\begin{array}{l}\text { human PLM, pig } \\
\left(\alpha_{1}, \beta_{1}\right)\end{array}$ & ND & $1,1,1$ & SMD1165 \\
\hline $\begin{array}{l}\text { Na/K-ATPase }\left(\alpha_{1}, \beta_{1}\right) \\
\text { (coexpression) }\end{array}$ & human, pig & ND & 10,1 & SMD1165 \\
\hline $\begin{array}{l}\text { Cytochrome P450 } 17 \alpha- \\
\text { hydroxylase CYP17 }\end{array}$ & human & 54 & ND & GS115 \\
\hline $\begin{array}{l}\text { Apo and GSH-complexed } \\
\text { leukotriene } \mathrm{C}_{4} \text { synthase LTC4S }\end{array}$ & human & ND & 4 & KM71H \\
\hline $\begin{array}{l}\text { Na/K-ATPase }\left(\alpha_{3}, \beta_{1}\right) \\
\text { (coexpression) }\end{array}$ & pig & $110 / 44$ & 10,1 & $\begin{array}{l}\text { GS115, } \\
\text { SMD1168 }\end{array}$ \\
\hline Monoamine oxidase B MAOB & rat & 60 & 1 & KM71 \\
\hline Leukotriene $\mathrm{C}_{4}$ synthase LTC4S & rat & 18 & 4 & KM71 \\
\hline Monoamine oxidase A MAOA & rat & 60 & 1 & KM71 \\
\hline Monoamine oxidase MAO & zebrafish & 60 & 1 & KM71 \\
\hline Other membrane proteins & & & & \\
\hline Thromboplastin, tissue factor TF & rabbit & 31 & 1 & GS115 \\
\hline $\begin{array}{l}\text { Immunotoxin Cyt2Aa1 } \\
\text { (codon-optimized) }\end{array}$ & Bacillus thuringiensis & 60 & 1 ? & KM71 \\
\hline $\begin{array}{l}\text { Lectin-like oxLDL receptor } 1 \\
\text { hLOX-1 }\end{array}$ & human & 43 & 1 ? & GS115 \\
\hline
\end{tabular}




\begin{tabular}{|c|c|c|c|}
\hline $\begin{array}{l}\text { Vector constructs (plasmid } \\
\text { backbone) }\end{array}$ & Activity & Process & Reference \\
\hline (pPIC3.5K)-MAOA & P: $115 \mathrm{mg} / 1$ & CESPCS $(3 \AA)$ & [113] \\
\hline (pPICZA)-CPR-CYP2D6 & E: $8.8 \mathrm{pmol} / \mathrm{min} / \mathrm{pmol}$ enzyme & $\mathrm{CE}$ & {$[114]$} \\
\hline (pPICZB)-Cytb561-His ${ }_{6}$ & $\mathrm{~S}: 0.7 \mathrm{mg} / 1, \mathrm{P}: 2.7 \mathrm{mg}$ & CESP & [115] \\
\hline (pPICZA)-PcCYP1f & ND & $\mathrm{CE}$ & [116] \\
\hline $\begin{array}{l}\text { (pHIL-D2)- } \alpha_{1} / \mathrm{His}_{10}-\beta_{1} \\
\text { (pGAPZA)-PLM }\end{array}$ & ATPase activity & CESP & [43] \\
\hline (pHIL-D2)- $\boldsymbol{\alpha}_{1} / \mathrm{His}_{10}-\beta_{1}$ & S: $8-16 \mu \mathrm{mol} /$ & CESP & [41] \\
\hline (pPIC3.5K)-CYP17(His) & $\mathrm{E}: 300 \mathrm{pmol} / \mathrm{s}$ & CES & [117] \\
\hline (pPICZA)-His ${ }_{6}-\mathrm{LTC} 4 \mathrm{~S}$ & ND & $\operatorname{CESPCS}(2,2.15 \AA)$ & [118] \\
\hline$(\mathrm{pAO} 815)-\alpha_{3} / \beta_{1}$ & $\mathrm{E}: 0.23 \mathrm{mg} / \mathrm{l}$ & CESP & {$[42]$} \\
\hline (pPIC3.5K)-МАОВ & oxidase activity, P: $100 \mathrm{mg} / 0.51$ & CESP & [119] \\
\hline (pPICZA)-His ${ }_{6}-\mathrm{LTC} 4 \mathrm{~S}$ & $\mathrm{P}: 1 \mathrm{mg} / \mathrm{l}, 49 \mu \mathrm{mol} / \mathrm{mg} / \mathrm{min}$ & CESPC & [120] \\
\hline (pPIC3.5K)-MAOA & E: $700 \mathrm{U} / 1, \mathrm{P}: 200 \mathrm{mg} / \mathrm{l}$ & CESP & [121] \\
\hline (pPIC3.5K)-zMAO & P: $200 \mathrm{mg} / \mathrm{l}, 300 \mathrm{U} / \mathrm{l}$ & CESP & [122] \\
\hline (pIL-D26)-PHO1-TF-His 6 & P: $0.1 \mathrm{mg} / \mathrm{g}$ cells & CESP & [123] \\
\hline $\begin{array}{l}\text { (pPICZB)-CsFvC6.5- } \\
\text { synCyt2Aa1-c-Myc-His }{ }_{6}\end{array}$ & cytotoxic activity, P: $10 \mathrm{mg} / \mathrm{l}$ & CESP & [124] \\
\hline (pPIC9K)-AF-hLOX-1-His & ND & CESP & [125] \\
\hline
\end{tabular}




\begin{tabular}{|c|c|c|c|c|}
\hline Protein name & Organism & $\mathrm{kDa}$ & $\begin{array}{l}\text { Transmembrane } \\
\text { domains }\end{array}$ & Strains \\
\hline $\begin{array}{l}\text { Metal-dependent hydrolase } \\
\text { PAB } 0107\end{array}$ & Pyrococcus abyssi & $20-46$ & 5 & $\mathrm{X}-33$ \\
\hline Chloride channel PAB2010 & & & 10 & \\
\hline $\begin{array}{l}\text { Putative membrane protein } \\
\text { PAB0965 }\end{array}$ & & & 3 & \\
\hline $\mathrm{Fe}^{3+} \mathrm{ABC}$ protein $\mathrm{PAB} 0677$ & & & 9 & \\
\hline $\begin{array}{l}\text { Carbohydrate transport protein } \\
\text { PAB0724 }\end{array}$ & & & 9 & $\nabla$ \\
\hline Tetraspanin hCD81 & human & 26 & 4 & X-33, GS115 \\
\hline $\begin{array}{l}\text { Peroxisomal membrane protein } \\
22 \text { PMP22 }\end{array}$ & rat & 22 & 4 & SMD1163 \\
\hline $\begin{array}{l}\text { Tetraspanin peripherin/RDS p/ } \\
\text { RDS }\end{array}$ & ND & 37 & & KM71 \\
\hline $\begin{array}{l}\text { Epidermal growth factor receptor } \\
2 \text { HER-2/neu }\end{array}$ & human & 200 & 1 & $\mathrm{X}-33$ \\
\hline \multicolumn{2}{|c|}{$\begin{array}{l}\text { In the vector constructs column: } \mathrm{His}_{6}, \mathrm{His}_{8}, \mathrm{His}_{10} \text {, } \\
\text { hexa-, octa-, deca-istidine tag; AF, } \alpha \text { factor secretion } \\
\text { signal; CBP, calmodulin binding peptide; gly3, } \\
\text { triglycine tag; strep, streptavidin tag; strepII, StrepII } \\
\text { tag (MAWSHPQFEK); 1D4, 1D4 antibody recognition } \\
\text { sequence (TETSQVAPA); HA, hemagglutinin A tag; }\end{array}$} & \multicolumn{3}{|c|}{$\begin{array}{l}\text { c-Myc, C-terminal } m \gamma c \text { epitope (EQKLISEEDL); FLAG, } \\
\text { FLAG tag; bio, biotin acceptor domain. } \\
\text { In the process column CESPCS: C, cloning; E, expression; } \\
\text { S, solubilization; P, purification; C, cristallization; S, } \\
\text { structure. } \\
\text { Other: ND, not determined. }\end{array}$} \\
\hline
\end{tabular}

Moreover, this list not only reports on expression evaluations in P. pastoris but also covers solubilization, purification, crystallization, and structural studies of membrane proteins produced with this system. Remarkably, high-resolution structures for a dozen of them were thus obtained (see CEPSCS-labeled references in Table 3.3), which represents about one-third of the recombinantly produced eukaryotic membrane proteins for which a three-dimensional structure is available as of January 2010 (http://blanco.biomol.uci.edu/Membrane_Proteins_xtal.html). Overall, these records highlight $P$. pastoris as one of the most performant heterologous expression system for the structural studies of eukaryotic membrane proteins.

\section{5 .2}

\section{Common Trends for an Efficient Expression of Membrane Proteins in P. pastoris}

The basic experimental data recorded in Table 3.3 are intended to give some general directions to help the reader in the choice of an adapted procedure to start with for his/her favorite membrane protein to be expressed in P. pastoris. 


\begin{tabular}{|c|c|c|c|}
\hline $\begin{array}{l}\text { Vector constructs (plasmid } \\
\text { backbone) }\end{array}$ & Activity & Process & Reference \\
\hline $\begin{array}{l}(\mathrm{pPICZB} / \mathrm{pPICZa}) \pm \\
\text { AF-MP-c-Myc-His } \\
6\end{array}$ & ND & CESP & {$[126]$} \\
\hline (pPICZB)-hCD81-His 6 & $\mathrm{P}: 1.75 \mathrm{mg} / \mathrm{l}$ & CESP & [127] \\
\hline (pPICZA)-His 10 -PMP22 & P: $90 \mathrm{mg} / 41$ & CESP & {$[128]$} \\
\hline (pPICZA)-p/RDS-c-Myc-His ${ }_{6}$ & P: $0.3 \mathrm{mg} / \mathrm{l}$ & CESP & [129] \\
\hline $\begin{array}{l}\text { (pPICZaA)-AF-HER-2/neu-c- } \\
\text { Myc-His }\end{array}$ & ND & CE & [130] \\
\hline
\end{tabular}

Regarding the plasmidic constructs to select, nearly all kinds of available expression vectors have been assayed, most exclusively based on the $\mathrm{P}_{\mathrm{AOX} 1}$ inducible promoter. To our knowledge, only three noticeable exceptions are reported on the use of vectors bearing the constitutive promoter $\mathrm{P}_{G A P}$ for the expression evaluation of membrane proteins, including the human intestinal peptide transporter hPEPT1 [51], the human phospholemman [43], and the rat vesicular glutamate transporter 1 VGLUT1 [65]. In all cases the expression levels were rather significant; however, no comparison was conducted on the benefit of such a constitutive expression over an inducible system.

Overall, no real tendency emerges in the choice of a given vector for a given type of membrane protein, except in the case of water channel proteins where pPICZ constructs were always privileged. Similarly, whereas a secretion sequence is quite systematically added upstream of GPCR open reading frames (ORFs) for an enhanced expression of functional proteins, there is no apparent rule for all the other reported membrane proteins whatever their topology and orientation in the membrane. In the case of the six-transmembrnae domain aquaporins, for instance, where $\mathrm{N}$ - and C-termini are intracellularly located, protein expression has been evaluated with or without a fused secretion sequence and both situations proved efficient enough to obtain high-resolution structures of the produced protein ([79] versus $[72,76,80])$. 
As for several other expression systems, a large panel of tag sequences are frequently inserted to improve the downstream detection and purification steps, ranging from hexa- or decahistidine (the most widely employed tags), c-Myc, FLAG, HA and StrepII epitopes, to larger peptidic domains such as a biotinylation domain (bio), a calmodulin binding domain (CBD), or the fluorescent protein GFP. In addition, protease cleavage sequences are sometimes included in the constructs such as the Factor Xa or tobacco etch virus (TEV) sequences in order to eliminate the fused tags after or during [102] the purification step.

Nearly all commercially available strains have been used to express membrane proteins. While the criteria used for the choice of a given strain are generally not documented, few studies reported on the membrane protein-dependent differential behavior of strains - a phenomenon that is commonly observed. SMD1163, KM71, and X-33 indeed appeared more performant than GS115 for the expression of a GPCR [38], an ATP-binding cassette (ABC) transporter [49], and a tetraspanin [127], respectively, whereas GS115 performed better than SMD1168 for the recombinant expression of a serotonin transporter [20]. Alternatively, no real variation of the expression level could be observed when a GPCR, the $\mu$-opioid receptor, was evaluated in the X-33, GS115, SMD1163, and SMD1168 strains [87].

In most of the reported studies, functional expression levels of membrane proteins are assessed through both specific immunodetection tests and activity assays. In the situation where these parameters can be compared, as in the particular case of GPCRs, the outcome highlights a very fluctuating performance of the system that not only depends on the expressed membrane protein, but also on the experimental conditions assayed. Therefore, optimization of the expression conditions is often very helpful for the recovery of higher amounts of functional recombinant membrane proteins. This is the issue of the next section that aims at illustrating how expression levels can be enhanced with GPCRs as model membrane proteins.

\section{6}

\section{Guidelines for Optimizing Membrane Protein Expression in P. pastoris Using GPCRs as Models}

From the seminal work of Weiss et al. [38], more than 30 original articles focusing on GPCR expression in P. pastoris have been published so far. This wealth of quantitative and qualitative information relative to hundreds of different receptors from the same membrane protein family represents an ideal source of data to exemplify the different directions that can be undertaken to enhance the expression levels of membrane proteins. Different experimental adjustments conducted in several of these studies indeed proved highly beneficial. They can be divided into two main categories that are detailed below: those allowing us to design and to select for the most performing clones, and those implemented at the level of growth and induction. In addition, some considerations on optimizing yeast cell lysis are also briefly discussed. 
3.6.1

\section{Design and Selection of Enhanced Expression Clones}

As a general rule in heterologous expression studies, optimizing the coding sequence of the gene to be expressed is often very helpful. For instance, fitting the gene sequence to the codon usage of the host organism has generally shown a beneficial impact on expression levels (reviewed in [131]). In the case of GPCRs expressed in P. pastoris, a codon-optimized human $\beta_{2}$-adrenergic receptor $\left(\beta_{2} \mathrm{AR}\right)$ exhibited an activity of $6 \mathrm{pmol} / \mathrm{mg}$ in total membrane preparations [96] - a figure to be compared with the $24 \mathrm{pmol} / \mathrm{mg}$ functional receptors that were obtained for a nonoptimized human $\beta_{2} \mathrm{AR}$ expressed in a quite similar context [19]. This codonoptimization engineering of a GPCR thus did not appear really profitable, albeit this single reported approach may probably not be representative and more data are needed. Similarly, with the double goal of improving expression levels and receptor homogeneity, direct mutagenesis of potential $\mathrm{N}$-glycosylated residues was evaluated on several GPCRs and revealed a rather average outcome: whereas the receptor homogeneity was generally enhanced, the specific activity of the receptors was lowered in most cases [22, 95], only few of them being improved [22, 84] or remaining unchanged [90]. Larger sequence modifications were also reported, showing important beneficial effects for a C-terminally truncated adenosine $A_{2 A}$ receptor [132] and for a 47-amino-acid deletion of an internal loop for an acetylcholine muscarinic receptor [22], but with no real impact on expression levels in the case of a N-terminal deletion of a $\mu$-opioid receptor $[103,133]$.

Introducing additional fusion sequences may sometimes reveal a fruitful way to increase expression of GPCRs. Several studies notably compared the benefit of secretion signals added upstream the gene of interest, showing a very substantial effect of the signal sequence of the $\alpha$-factor from S. cerevisiae on the expression levels of a serotonergic [38], an opioid [103, 133], and a dopaminergic [90] receptor. This signal sequence is since systematically inserted for GPCR expression.

Addition of short tag sequences including the hexa- or decahistidine, FLAG or the c-Myc regularly proved very useful for the downstream detection and/or purification procedures of GPCRs, but did not result in significant changes in their expression levels. Similarly, GFP fused to several GPCRs either C-terminally [85, $98,99]$ or N-terminally $[103,104]$ did not markedly modify their expression profile. Instead, the GFP fusion appeared a useful multipurpose tool for (i) the selection of overexpressing clones, (ii) the determination of total recombinant protein expression, (iii) the evaluation of solubilization and purification conditions, and (iv) the subcellular localization of the receptors.

Interestingly, a significantly increased production level was observed when the biotinylation domain of the transcarboxylase from Propionibacterium shermanii was fused to the C-terminus of several receptors. For instance, for 5- $\mathrm{HT}_{5 \mathrm{~A}}[19]$, human ETB endothelin receptor (ETBR) [85], DRD2 [90], and $\beta_{2} \mathrm{AR}$ (C. Reinhart, personal communication) the number of active receptors per cell was more than doubled. In addition, the absence of this sequence from the GPCR constructs used in the study of Yurugi-Kobayashi et al. [22] probably participated to the lower expression 
levels observed for several of them when compared to the same receptors bearing this biotinylation domain [97]. Addition of this domain likely stabilized the recombinant receptor either by protecting the receptor from direct degradation or maintaining folding fidelity to avoid the unfolded protein response.

Regarding the choice of the cellular host to use, several studies compared the benefit of one strain over the others. For instance, the receptors $5-\mathrm{HT}_{5 \mathrm{~A}}$ and ETA were respectively expressed at higher levels in the protease-deficient strains SMD1163 [38] and SMD1168 [134] than in the GS115 strain (see Table 3.1 for the description of the strains). Similarly, the strain SMD1168 appeared a most appropriate host for the expression of a CB2 receptor when compared to the strain X-33 [101]. In several other cases, however, no significant differences were observed, and strains from the SMD series were mainly retained because of their proteasedeficient properties and their inherent lower impact on protein degradation during the downstream preparative steps.

In addition, since multicopy integration events occur with a relatively high frequency in P. pastoris transformants, gene dosage is also an important issue that directly impacts expression levels. For instance, a panel of clones resistant to increasing concentrations of zeocin [88] and G418 (geneticine) [19, 90] was selected for its representative content of integrated GPCR gene copy number. These studies and others show that the levels of active receptors increased correlatively with the number of integrated copies up to a plateau after which additional copies had no effect. Most importantly, from our observations (unpublished data), clones bearing the highest antibiotic resistance levels (i.e., the highest copy number of GPCRs genes) were often those presenting the highest amounts of immunodetected receptors, whereas ligand-binding activities were not improved. Such clones are thus generally not desired as they display a large proportion of nonfunctional receptors. Moreover, these observations strongly suggest that the bottleneck for the production of functional receptors lies in folding and/or post-translational processing rather than in the transcription and translation steps. As a consequence, clone selection procedures have to rely both on a representative phenotypic screening followed by an appropriate evaluation of the receptor quantity and activity.

\subsection{2}

\section{Optimization of the Expression Conditions}

Once the most performant clones have been selected, further improvements can be implemented by appropriately adjusting some of the experimental parameters that influence the host cell physiology, and hence its performance for heterologous gene expression, correct protein folding, and proper trafficking. These external factors include culture format and procedures, temperature and time of induction, cell densities, formulation of growth media, or supplementation with stabilizing compounds or chemical chaperones.

As a first step, evaluating the production time course of a GPCR is often very useful as the outcome may vary importantly from one receptor to another. For 
instance, $10 \mathrm{~h}$ was determined as the optimal induction time for different constructs expressing a $\mu$-opioid receptor [87], whereas the highest expression levels were obtained in the range of $18-24 \mathrm{~h}$ postinduction for a majority of other receptors and up to $60 \mathrm{~h}$ for an engineered ACM2 muscarinic receptor [22]. Similarly, while the induction phase in methanol-containing media is usually performed using cell densities of about $5 \times 10^{7}$ cells $/ \mathrm{ml}\left(1 \mathrm{OD}_{600} / \mathrm{ml}\right)$, we observed that this parameter was differently affecting the expression level of GPCRs, higher cell densities (up to $10 \mathrm{OD}_{600} / \mathrm{ml}$ ) being actually more appropriate for several of them (unpublished data).

Formulation of the induction media is also an important issue. Adjustments in the composition of buffered media, $\mathrm{pH}$ values, and methanol concentration usually did not bring major benefits in GPCR expression, and a typical induction is generally performed at $\mathrm{pH} 5-7$ in buffered complex media containing $0.5 \%$ methanol. Much more substantial improvements, however, can be gained by supplementing these media with some small compounds that are believed to facilitate the folding and processing of the recombinant proteins. Among these molecules, dimethyl sulfoxide (DMSO) added in the induction medium remarkably increased the production yield of 16 out of 20 tested receptors up to 6 -fold relative to standard conditions [94]. Similar effects were observed in other studies evaluating GPCR expression not only in the $P$. pastoris system [21, 100], but also using mammalian [21] or insect [135] cells hosts. The precise role of DMSO here is not clear, but it has been shown to dramatically alter the membrane properties of several organisms by increasing their permeability [136], thus possibly influencing the processes of membrane protein translocation. DMSO is also thought to act as a stabilizer of folding intermediates and has been already qualified a chemical chaperone [137]. In a comparable fashion, adding ligands specific to a given GPCR proved highly beneficial for a large majority of tested receptors [19, 90, 94]. In the case of a histaminergic $\mathrm{H}_{2}$ receptor, the expression level was improved up to 7-fold in the presence of an antagonist compound, cimetidine, in the induction medium [94]. Such small molecules are considered pharmacological chaperones as they have been shown to selectivity promote the proper folding and trafficking of the targeted GPCR [137], therefore limiting the recurrent complications related to misfolding/aggregation and misfolding/degradation pathways.

In addition, it was shown in several studies that lowering temperature during expression to a typical range of $18-24^{\circ} \mathrm{C}$ was optimal for various receptors, as measured by ligand binding [22, 87, 90, 94, 95]. Possible explanations for the temperature effect include slowing down protein production and not overloading the translocation machinery, protein processing, or intracellular trafficking. Lowering temperature has also been shown to reduce proteolytic activities and upregulate cold shock proteins such as chaperones.

As illustrated in a work we conducted on a selection of 20 GPCRs [94], adjusting these different parameters at the culturing level always turned out beneficial and every tested clones revealed higher ligand binding values $\left(B_{\max }\right)$ compared with the standard condition. Strikingly, eight out of these 20 receptors revealed high $B_{\max }$ values (above $20 \mathrm{pmol} / \mathrm{mg}$ ) after optimization. In addition, we and others also 
found that the amount of functional receptor (in terms of ligand binding) did not scale with the total amount of receptors evaluated either by immunodetection [94] or by fluorescence [88] measurements. Most importantly, the total amount of receptors was not changed after optimization while the total number of binding sites $\left(B_{\max }\right)$ was increased from 1.3 - to more than 8 -fold. These data are all in agreement with the concept that GPCRs are expressed in P. pastoris under a functional/ nonfunctional equilibrium that can be modulated with the expression conditions that are used.

\section{6 .3}

\section{Yeast Cell Lysis}

As a common trait of budding yeasts, $P$. pastoris possesses a thick protective cell wall that requires the use of aggressive disruption methods for the recovery and preparation of the membrane protein-containing fractions. The choice of a cell lysis method suited to P. pastoris cultured in various volumes and formats is therefore nontrivial, albeit very few studies report on this important issue [27]. We here indicate a selection of techniques and apparatus references that we and others found the most adapted to this key step.

Shearing-based methods involving microbeads are mostly preferred as they are very efficient, compatible with a broad range of sample volumes, and directly accessible to most of the standard-equipped labs. In the simplest and widest used mode, cells are violently shaken with $500-\mu \mathrm{m}$ diameter beads in cold buffers using a basic vortex apparatus in cycles alternating shaking and ice-cooling phases $([38,138]$ among others). In order to achieve more reliable and reproducible results, programmable equipment is recommended, such as the Tissue Lyser from Qiagen [132] or the FastPrep 24 from MP Biomedicals [102] that accommodate various sample volumes and formats (up to $50 \mathrm{ml}$ ), or the more sophisticated and expensive grinder series from Dyno Mills [85] that can operate using large volumes both in batch or continuous modes. In addition, pressure-based instruments have also proven efficient for the lysis of $P$. pastoris cells, and besides the well-known French pressure cell press stands a panel of cell disruptors from Constant Systems that can handle from 1 to $20 \mathrm{ml}$ of batch samples and more than $500 \mathrm{ml} / \mathrm{min}$ with the continuous flow models. Alternatively, methods involving glucanase enzymes (e.g., helicase from snail digestive juice; zymolyase or lyticase from microbial sources) can be used to remove the cell wall and give rise to spheroplast preparations that can be easily burst. For cost and practical reasons, however, these methods are obviously not recommended for the lysis of large cell volumes.

Noteworthy, we and others commonly observed that the longer the induction phase, the less efficient the lysis step. This is likely to be related to the very dynamic nature of the cell wall that can adapt to various physiological changes in order to maintain the integrity of yeast cells and prevent them from lysis [139]. This issue is notably to be considered when optimizing the induction time, which should ideally strike a balance between expression level and cell lysis efficiency. 
3.7

\section{Conclusions and Future Directions}

Overall, $P$. pastoris appears a very efficient heterologous system for the production of a large panel of membrane proteins. Importantly, a series of various optimizations including gene and vector sequence engineering, host strains, clone selection, culture format and procedures, temperature and time of induction, cell densities, formulation of growth media, and supplementation with stabilizing compounds or chemical chaperones, always prove very helpful for improving expression levels and protein functionality. As an exemplar illustration of such improvements, the functional expression level of a dopaminergic $\mathrm{D}_{2 \mathrm{~S}}$ GPCR was increased from about 1000 receptors per cell for an unmodified receptor up to more than 50000 receptors per cell for an ultimate engineered $\alpha$ FD2SBio receptor [90].

Even if some general tips emerge, the outcome is, however, often a matter of membrane protein-dependent adjustments and successes still often rely on trialand-error strategies. An improved success rate will certainly be obtained in the coming years with a more rationalized use of $P$. pastoris, taking advantage of recent breakthroughs. Very recently, the combination of proteomics and genetics brought some mechanistic insights into the biology of recombinant production of membrane proteins both in E. coli [140] and S. cerevisiae [141], and subsequently allowed the engineering of strains presenting a specific task-adapted physiology and enhanced production properties. Such strain evolution strategies have been already applied to $P$. pastoris, notably for the production of human glycoproteins in glycoengineered strains [23]. They will be probably further exploited with the recent release of the whole-genome sequence of $P$. pastoris [9] that is now fully accessible to proteomic analyses and genetic manipulations.

\section{Acknowledgments}

The authors are supported by the CNRS and the University of Strasbourg, and by grants from the French National Research Agency (ANR-06-PCVI-0008 and ANR- 07-PCVI-0024).

\section{Abbreviations}

$\beta_{2} \mathrm{AR} \quad \beta_{2}$-adrenergic receptor

$\mathrm{ABC} \quad$ ATP-binding cassette

CBD calmodulin binding domain

DMSO dimethyl sulfoxide

GFP Green Fluorescent Protein

GPCR G-protein-coupled receptor

ORF open reading frame

TEV tobacco etch virus 


\section{References}

1 Phaff, H.J. and Starmer, W.T. (1987) Yeasts associated with plants, insects and soil, in The Yeasts, Volume 1: Biology of Yeasts, 2nd edn (eds A.H. Rose and J.S. Harrison), Academic Press, Orlando, FL, pp. 123-180.

2 Guilliermond, C.H. (1919) Seances. Mem. Soc. Biol., 82, 466-470.

3 Ogata, K., Nishikawa, H., and Ohsugi, M. (1969) A yeast capable of utilizing methanol. Agric. Biol. Chem., 33, 1519-1520.

4 Wegner, G.H. (1990) Emerging applications of methylotrophic yeast. FEMS Microbiol. Rev., 7, 279-284.

5 Cereghino, J.L. and Cregg, J.M. (2000) Heterologous protein expression in the methylotrophic yeast Pichia pastoris. FEMS Microbiol. Rev., 24, 45-66.

6 Macauley-Patrick, S., Fazenda, M.L., McNeil, B., and Harvey, L.M. (2005) Heterologous protein production using the Pichia pastoris expression system. Yeast, 22, 249-270.

7 Yamada, Y., Matsuda, M., Maeda, K., and Mikata, K. (1995) The phylogenetic relationships of methanol-assimilating yeasts based on the partial sequences of 18S and 26S ribosomal RNAs: the proposal of Komagataella gen. nov. (Saccharomycetaceae). Biosci. Biotechnol. Biochem., 59, 439-444.

8 Kurtzman, C.P. (2009) Biotechnological strains of Komagataella (Pichia) pastoris are Komagataella phaffi as determined from multigene sequence analysis. $J$. Ind. Microbiol. Biotechnol., 36 1435-1438.

9 De Schutter, K., Lin, Y.C., Tiels, P., Van Hecke, A., Glinka, S., Weber-Lehmann, J., Rouze, P., Van de Peer, Y., and Callewaert, N. (2009) Genome sequence of the recombinant protein production host Pichia pastoris. Nat. Biotechnol., 27, 561-569.

10 Cereghino, G.P.L., Cereghino, J.L., Ilgen, C., and Cregg, J.M. (2002) Production of recombinant proteins in fermenter cultures of the yeast Pichia pastoris. Curr. Opin. Biotechnol., 13, 329-332.
11 Li, P., Anumanthan, A., Gao, X.G., Ilangovan, K., Suzara, V.V., Düzgünes, N., and Renugopalakrishnan, V. (2007) Expression of recombinant proteins in Pichia pastoris. Appl. Biochem. Biotechnol., 142, 105-124.

12 Eckart, M.R. and Bussineau, C.M. (1996) Quality and authenticity of heterologous proteins synthesized in yeast. Curr. Opin. Biotechnol., 7, 525-530.

13 Wheatley, M. and Hawtin, S.R. (1999) Glycosylation of G-protein-coupled receptors for hormones central to normal reproductive functioning: its occurence and role. Hum. Reprod., 5 , 356-364.

14 Duvernay, M.T., Filipeanu, C.M., and Wu, G. (2005) The regulatory mechanisms of export trafficking of $\mathrm{G}$ protein-coupled receptors. Cell. Signal. 17, 1457-1465.

15 Cohen, D.M. (2006) Regulation of TRP channels by $N$-linked glycosylation. Semin. Cell. Dev. Biol., 17, 630-637.

16 Grinna, L.S. and Tschopp, J.F. (1989) Size distribution and general structural features of $\mathrm{N}$-linked oligosaccharides from the methylotrophic yeast, Pichia pastoris. Yeast, 5, 107-115.

17 Wood, M.J. and Komives, E.A. (1999) Production of large quantities of isotopically labeled protein in Pichia pastoris by fermentation. J. Biomol. NMR, 13, 149-159.

18 Whittaker, M.M. and Whittaker, J.W. (2005) Construction and characterization of Pichia pastoris strains for labeling aromatic amino acids in recombinant proteins. Protein Expr. Purif., 41, 266-274.

19 Weiss, H.M., Haase, W., Michel, H., and Reilander, H. (1998) Comparative biochemical and pharmacological characterization of the mouse $5 \mathrm{HT}_{5 \mathrm{~A}}$ 5 -hydroxytryptamine receptor and the human $\beta_{2}$-adrenergic receptor produced in the methylotrophic yeast Pichia pastoris. Biochem. J., 330, 1137-1147.

20 Tate, C.G., Haase, J., Baker, C. Boorsma, M., Magnani, F., Vallis, Y., and Williams, D.C. (2003) Comparison 
of seven different heterologous protein expression systems for the production of the serotonin transporter. Biochim. Biophys. Acta, 1160, 141-153.

21 Shukla, A.K., Haase, W., Reinhart, C., and Michel, H. (2007) Heterologous expression and comparative characterization of the human neuromedin U subtype II receptor using the methylotrophic yeast Pichia pastoris and mammalian cells. Int. J. Biochem. Cell Biol., 39, 931-942.

22 Yurugi-Kobayashi, T., Asada, H., Shiroishi, M., Shimamura, T., Funamoto, S., Katsuta, N., Ito, K., Sugawara, T., Tokuda, N., Tsujimoto, H., Murata, T., Nomura, N., Haga, K., Haga, T., Iwata, S., and Kobayashi, T. (2009) Comparison of functional non-glycosylated GPCRs expression in Pichia pastoris. Biochem. Biophys. Res. Commun., 380, 271-276.

23 Hamilton, S.R. and Gerngross, T.U. (2007) Glycosylation engineering in yeast: the advent of fully humanized yeast. Curr. Opin. Biotechnol., 18, 387-392.

24 Opekarova, M. and Tanner, W. (2003) Specific lipid requirements of membrane proteins - a putative bottleneck in heterologous expression. Biochim. Biophys. Acta, 1610, 11-22.

25 Lifshitz, Y., Petrovich, E., Haviv, H., Goldshleger, R., Tal, D.M., Garty, H., and Karlish, S.J.D. (2007) Purification of the human $\alpha 2$ isoform of $\mathrm{Na}, \mathrm{K}$-ATPase expressed in Pichia pastoris. Stabilization by lipids and FXYD1. Biochemistry, 46, 14937-14950.

26 Marx, H., Sauer, M., Resina, D., Vai, M., Porro, D., Valero, F., Ferrer, P., and Mattanovich, D. (2006) Cloning, disruption and protein secretory phenotype of the GAS1 homologue of Pichia pastoris. FEMS Microbiol. Lett., 264, 40-47.

27 Hopkins, T.R. (1991) Physical and chemical cell disruption for the recovery of intracellular proteins. Bioprocess Technol., 12, 57-83.

28 Resina, D., Maurer, M., Cos, O., Arnau, C., Carnicer, M., Marx, H., Gasser, B., Valero, F., Mattanovich, D., and Ferrer, P. (2009) Engineering of bottlenecks in \begin{tabular}{l|l} 
References & 101
\end{tabular}

Rhizopus oryzae lipase production in Pichia pastoris using the nitrogen source-regulated FLD1 promoter. Nat. Biotechnol., 25, 396-403.

29 Daly, R. and Hearn, M.T.W. (2005) Expression of heterologous proteins in Pichia pastoris: a useful experimental tool in protein engineering and production. J. Mol. Recognit., 18, 119-138.

30 Gellisen, G. (2000) Heterologous protein production in methylotrophic yeasts. Appl. Microbiol. Biotechnol., 54, 741-750.

31 Hartner, F.S., Ruth, C., Langenegger, D., Johnson, S.N., Hyka, P., LinCereghino, G.P., Lin-Cereghino, J., Kovar, K., Cregg, J.M., and Glieder, A. (2008) Promoter library designed for fine-tuned gene expression in Pichia pastoris. Nucleic Acids Res., 36, e76.

32 Cregg, J.M., Barringer, K.J., Hessler, A.Y., and Madden, K.R. (1985) Pichia pastoris as a host system for transformations. Mol. Cell. Biol., 5 3376-3385.

33 Lee, C.C., Williams, T.G., Wong, D.W.S., and Robertson, G.H (2005) An episomal expression vector for screening mutant gene libraries in Pichia pastoris. Plasmid, 54, 80-85.

34 Hong, I.P., Lee, S.J., Kim, Y.S., and Choi, S.G. (2007) Recombinant expression of human cathelicidin (hCAP18/LL-37) in Pichia pastoris. Biotechnol. Lett., 29, 73-78.

35 Sandstrom, A.G., Engstrom, K., Nyhlen, J., Kasrayan, A., and Backvall, J.E. (2009) Directed evolution of Candida antarctica lipase A using an episomal replicating yeast plasmid. Protein Eng. Des. Sel., 22, 413-420.

36 Pla, I.A., Damasceno, L.M., Vannelli, T., Ritter, G., Batt, C.A., and Shuler, M.L. (2006) Evaluation of $\mathrm{Mut}^{+}$and $\mathrm{Mut}^{\mathrm{S}}$ Pichia pastoris phenotypes for high level extracellular scFv expression under feedback control of the methanol concentration. Biotechnol. Prog., 22, 881-888.

37 Cos, O., Ramón, R., Montesinos, J.L., and Valero, F. (2006) Operational strategies, monitoring and control of heterologous protein production in the methylotrophic yeast Pichia pastoris 
under different promoters: a review. Microb. Cell Fact., 5, 17.

38 Weiss, H.M., Haase, W., Michel, H., and Reilander, H. (1995) Expression of functional mouse $5-\mathrm{HT}_{5 \mathrm{~A}}$ serotonin receptor in the methylotrophic yeast Pichia pastoris: pharmacological characterization and localization. FEBS Lett., 377, 451-456.

39 Strugatsky, D., Gottschalk, K.E., Goldshleger, R., Bibi, E., and Karlish, S.J.D. (2003) Expression of $\mathrm{Na}^{+}$, $\mathrm{K}^{+}$-ATPase in Pichia pastoris: analysis of wild type and D369N mutant proteins by $\mathrm{Fe}^{2+}$-catalyzed oxidative cleavage and molecular modeling. J. Biol. Chem., 278, 46064-46073.

40 Cohen, E., Goldshleger, R., Shainskaya, A., Tal, D.M., Ebel, C., Le Maire, M., and Karlish, S.J.D. (2005) Purification of Na,K-ATPase expressed in Pichia pastoris reveals an essential role of phospholipid-protein interactions. $J$. Biol. Chem., 280, 16610-16618.

41 Haviv, H., Cohen, E., Lifshitz, Y., Tal, D.M., Goldshleger, R., and Karlish, S.J.D. (2007) Stabilization of $\mathrm{Na}^{+}, \mathrm{K}^{+}$ATPase purified from Pichia pastoris membranes by specific interactions with lipids. Biochemistry, 46, 12855-12867.

42 Reina, C., Padoani, G., Carotti, C., Merico, A., Tripodi, G., Ferrari, P., and Popolo, L. (2007) Expression of the $\alpha 3 / \beta 1$ isoform of human $\mathrm{Na}, \mathrm{K}-\mathrm{ATPase}$ in the methylotrophic yeast Pichia pastoris. FEMS Yeast Res., 7, 585-594.

43 Lifshitz, Y., Lindzen, M., Garty, H., and Karlish, S.J.D. (2006) Functional interactions of phospholemman (PLM) (FXYD1) with $\mathrm{Na}^{+}, \mathrm{K}^{+}$-ATPase: Purification of $\alpha 1 / \beta 1 /$ PLM complexes expressed in Pichia pastoris. J. Biol. Chem., 281, 15790-15799.

44 Parcej, D.N. and Eckhardt-Strelau, L. (2003) Structural characterization of neuronal voltage-sensitive $\mathrm{K}^{+}$channels heterologously expressed in Pichia pastoris. J. Mol. Biol., 333, 103-116.

45 Long, S.B., Campbell, E.B., and MacKinnon, R. (2005) Crystal structure of a mammalian voltage-dependent Shaker family $\mathrm{K}^{+}$channel. Science, 309, 897-903.
46 Long, S.B., Tao, X., Campbell, E.B., and MacKinnon, R. (2007) Atomic structure of a voltage dependent $\mathrm{K}^{+}$channel in a lipid membrane-like environment. Nature, 450, 376-382.

47 Julien, M., Kajiji, S., Kaback, R.H., and Gros, P. (2000) Simple purification of highly active biotinylated P-glycoprotein: enantiomer-specific modulation of drug-stimulated ATPase activity. Biochemistry, 39, 75-85.

48 Urbatsch, I.L., Gimi, K., Wilke-Mounts, S., and Senior, A.E. (2000) Conserved Walker A Ser residues in the catalytic sites of P-glycoprotein are critical for catalysis and involved primarily at the transition state step. J. Biol. Chem., 275, 25031-25038.

49 Cai, J., Daoud, R., Georges, E., and Gros, P. (2001) Functional expression of multidrug resistance protein 1 in Pichia pastoris. Biochemistry, 40, 8307-8316.

50 Chiou, T.J., Liu, H., and Harrison, M.J. (2001) The spatial expression patterns of a phosphate transporter (MtPT1) from Medicago truncatula indicate a role in phosphate transport at the root/soil interface. Plant J., 25, 281-293.

51 Theis, S., Doring, F., and Daniel, H. (2001) Expression of the Myc/His-tagged human peptide transporter hPEPT1 in yeast for protein purification and functional analysis. Protein Expr. Purif., 22, 436-442.

52 Urbatsch, I.L., Wilke-Mounts, S., Gimi, K., and Senior, A.E. (2001) Purification and characterization of $\mathrm{N}$-glycosylation mutant mouse and human P-glycoproteins expressed in Pichia pastoris cells. Arch. Biochem. Biophys., 388, 171-177.

53 Urbatsch, I.L., Gimi, K., Wilke-Mounts, S., Lerner-Marmarosh, N., Rousseau, M.E., Gros, P., and Senior, A.E. (2001) Cysteines 431 and 1074 are responsible for inhibitory disulfide cross-linking between the two nucleotide-binding sites in human P-glycoprotein. J. Biol. Chem., 276, 26980-26987.

54 Zhang, H., Howard, E.M., and Roepe, P.D. (2002) Analysis of the antimalarial drug resistance protein Pfcrt expressed in yeast. J. Biol. Chem., 277, 49767-49775. 
55 Urbatsch, I.L., Tyndall, G.A., Tombline, G., and Senior, A.E. (2003)

P-glycoprotein catalytic mechanism, studies of the ADP-vanadate inhibited state. J. Biol. Chem., 278, 23171-23179.

56 Mao, Q., Conseil, G., Gupta, A., Cole, S.P.C., and Unadkat, J.D. (2004) Functional expression of the human breast cancer resistance protein in Pichia pastoris. Biochem. Biophys. Res. Commun., 320, 730-737.

57 Tyagi, N.K., Goyal, P., Kumar, A., Pandey, D., Siess, W., and Kinne, R.K.H. (2005) High-yield functional expression of human sodium/D-glucose cotransporter 1 in Pichia pastoris and characterization of ligand-induced conformational changes as studied by tryptophan fluorescence. Biochemistry, 44, 15514-15524.

58 Aller, S.G. and Unger, V.M. (2006) Projection structure of the human copper transporter CTR1 at 6 -Å resolution reveals a compact trimer with a novel channel-like architecture. Proc. Natl. Acad. Sci. USA, 103, 3627-3632.

59 Diatloff, E., Forde, B.G., and Roberts, S.K. (2006) Expression and transport characterisation of the wheat low-affinity cation transporter (LCT1) in the methylotrophic yeast Pichia pastoris. Biochem. Biophys. Res. Commun., 344, 807-813.

60 Tan, W., Gou, D.M., Tai, E., Zhao, Y.Z., and Chow, L.M.C. (2006) Functional reconstitution of purified chloroquine resistance membrane transporter expressed in yeast. Arch. Biochem. Biophys., 452, 119-128.

61 Tombline, G., Urbatsch, I.L., Virk, N., Muharemagic, A., Bartholomew White, L., and Senior, A.E. (2006) Expression, purification, and characterization of cysteine-free mouse P-glycoprotein. Arch. Biochem. Biophys., 445, 124-128.

62 Amoah, L.E., Lekostaj, J.K., and Roepe, P.D. (2007) Heterologous expression and ATPase activity of mutant versus wild type PfMDR1 protein. Biochemistry, 46, 6060-6073.

63 Chloupková, M., Pickert, A., Lee, J.Y., Souza, S., Trinh, Y.T., Connelly, S.M., Dumont, M.E., Dean, M., and Urbatsch, I.L. (2007) Expression of 25 human ABC

\section{References

transporters in the yeast Pichia pastoris and characterization of the purified ABCC3 ATPase activity. Biochemistry, 46 7992-8003.

64 Price, D.R.G., Wilkinson, H.S., and Gatehouse, J.A. (2007) Functional expression and characterisation of a gut facilitative glucose transporter, NlHT1, from the phloem-feeding insect Nilaparvata lugens (rice brown planthopper). Insect Biochem. Mol. Biol. 37, 1138-1148

65 Cox, H.D., Chao, C.K., Patel, S.A., and Thompson, C.M. (2008) Efficient digestion and mass spectral analysis of vesicular glutamate transporter $1: a$ recombinant membrane protein expressed in yeast. J. Proteome Res., 7, 570-578.

66 Alisio, A. and Mueckler, M. (2010) Purification and characterization of mammalian glucose transporters expressed in Pichia pastoris. Protein Expr. Purif., 70, 81-87.

67 Aller, S.G., Yu, J., Ward, A., Weng, Y., Chittaboina, S., Zhuo, R., Harrell, P.M., Trinh, Y.T., Zhang, Q., Urbatsch, I.L., and Chang, G. (2009) Structure of P-glycoprotein reveals a molecular basis for poly-specific drug binding. Science, 323, 1718-1722.

68 Beckham, K.S.H., Potter, J.A., and Unkles, S.E. (2010) Formate-nitrite transporters: optimisation of expression, purification and analysis of prokaryotic and eukaryotic representatives. Protein Expr. Purif., 71, 184-189.

69 Karlsson, M., Fotiadis, D., Sjovall, S., Johansson, I., Hedfalk, K., Engel, A., and Kjellbom, P. (2003) Reconstitution of water channel function of an aquaporin overexpressed and purified from Pichia pastoris. FEBS Lett., 537, 68-72.

70 Kukulski, W., Schenk, A.D., Johanson, U., Braun, T., de Groot, B.L., Fotiadis, D., Kjellbom, P., and Engel, A. (2005) The $5 \AA$ structure of heterologously expressed plant aquaporin SoPIP2;1. J. Mol. Biol., 350, 611-616.

71 Daniels, M.J., Wood, M.R., and Yeager, M. (2006) In vivo functional assay of a recombinant aquaporin in Pichia pastoris. Appl. Environ. Microbiol., 72, 1507-1514 
72 Tornroth-Horsefield, S., Wang, Y.,

Hedfalk, K., Johanson, U., Karlsson, M., Tajkhorshid, E., Neutze, R., and Kjellbom, P. (2006) Structural mechanism of plant aquaporin gating. Nature, 439, 688-694.

73 Eifler, N., Duckely, M., Sumanovski, L.T., Egan, T.M., Oksche, A., Konopka, J.B., Luthi, A., Engel, A., and Werten, P.J.L. (2007) Functional expression of mammalian receptors and membrane channels in different cells. J. Struct. Biol., 159, 179-193.

74 Nyblom, M., Oberg, F., LindkvistPetersson, K., Hallgren, K., Findlay, H., Wikstrom, J., Karlsson, A., Hansson, O. Booth, P.J., Bill, R.M., Neutze, R., and Hedfalk, K. (2007) Exceptional overproduction of a functional human membrane protein. Protein Expr. Purif., 56, 110-120.

75 Hedfalk, K., Pettersson, N., Oberg, F., Hohmann, S., and Gordon, E. (2008) Production, characterization and crystallization of the Plasmodium falciparum aquaporin. Protein Expr. Purif., 59, 69-78.

76 Horsefield, R., Nordén, K., Fellert, M., Backmark, A., Tornroth-Horsefield, S., Terwisscha van Scheltinga, A.C., Kvassman, J., Kjellbom, P., Johanson, U., and Neutze, R. (2008) Highresolution X-ray structure of human aquaporin 5. Proc. Natl. Acad. Sci. USA, 105, 13327-13332.

77 Verdoucq, L., Grondin, A., and Maurel, C. (2008) Structure-function analysis of plant aquaporin AtPIP2;1 gating by divalent cations and protons. Biochem. J., 15, 409-416.

78 Azad, A.K., Sawa, Y., Ishikawa, T., and Shibata, H. (2009) Heterologous expression of tulip petal plasma membrane aquaporins in Pichia pastoris for water channel analysis. Appl. Environ. Microbiol., 75, 2792-2797.

79 Fischer, G., Kosinska-Eriksson, U. Aponte-Santamaria, C., Palmgren, M. Geijer, C., Hedfalk, K., Hohmann, S., de Groot, B.L., Neutze, R., and LindkvistPetersson, K. (2009) Crystal structure of a yeast aquaporin at $1.15 \AA$ reveals a novel gating mechanism. PLOS Biol., 7 , e1000130.
80 Ho, J.D., Yeh, R., Sandstrom, A., Chorny, I., Harries, W.E.C., Robbins, R.A., Miercke, L.J.W., and Stroud, R.M. (2009) Crystal structure of human aquaporin 4 at $1.8 \AA$ and its mechanism of conductance. Proc. Natl. Acad. Sci. USA, 106, 7437-7442.

81 Öberg, F., Ekvall, M., Nyblom, M., Backmark, A., Neutze, R., and Hedfalk, K. (2009) Insight into factors directing high production of eukaryotic membrane proteins; production of 13 human AQPs in Pichia pastoris. Mol. Membr. Biol., 26, 215-227.

82 Licata, L., Haase, W., Eckhardt-Strelau, L., and Parcej, D.N. (2006) Overexpression of a mammalian small conductance calcium-activated $\mathrm{K}^{+}$ channel in Pichia pastoris: effects of trafficking signals and subunit fusions. Protein Expr. Purif., 47, 171-178.

83 Tao, X., Avalos, J.L., Chen, J., and MacKinnon, R. (2009) Crystal structure of the eukaryotic strong inward-rectifier $\mathrm{K}^{+}$channel Kir2.2 at 3.1 Å resolution. Science, 326, 1668-1674.

84 Schiller, H., Haase, W., Molsberger, E., Janssen, P., Michel, H., and Reilander, H. (2000) The human ETB endothelin receptor heterologously produced in the methylotrophic yeast Pichia pastoris shows high-affinity binding and induction of stacked membranes. Receptors Channels, 7, 93-107.

85 Schiller, H., Molsberger, E., Janssen, P., Michel, H., and Reilander, H. (2001) Solubilization and purification of the human ETB endothelin receptor produced by high-level fermentation in Pichia pastoris. Receptors Channels, 7 , 453-569.

86 Feng, W., Cai, J., Pierce, W.M., Jr, and Song, Z.H. (2002) Expression of CB2 cannabinoid receptor in Pichia pastoris. Protein Expr. Purif., 26, 496-505.

87 Sarramegna, V., Demange, P., Milon, A., and Talmont, F. (2002) Optimizing functional versus total expression of the human $\mu$-opioid receptor in Pichia pastoris. Protein Expr. Purif., 24, 212-220.

88 Sarramegna, V., Talmont, F., Seree de Roch, M., Milon, A., and Demange, P. (2002) Green fluorescent protein as a reporter of human $\mu$-opioid receptor 
overexpression and localization in the methylotrophic yeast Pichia pastoris. J. Biotechnol., 99, 23-39.

89 De Jong, L.A.A., Grunewald, S., Franke, J.P., Uges, D.R.A., and Bischoff, R. (2004) Purification and characterization of the recombinant human dopamine D2S receptor from Pichia pastoris. Protein Expr. Purif., 33, 176-184.

90 Grunewald, S., Haase, W., Molsberger, E., Michel, H., and Reilander, H. (2004) Production of the human D2S receptor in the methylotrophic yeast $P$. pastoris. Receptors Channels, 10, 37-50.

91 De Rivoyre, M., Bonino, F., Ruel, L., Bidet, M., Thérond, P., and Mus-Veteau, I. (2005) Human receptor Smoothened, a mediator of Hedgehog signalling, expressed in its native conformation in yeast. FEBS Lett., 579, 1529-1533.

92 Kim, T.K., Zhang, R., Feng, W., Cai, J., Pierce, W., and Song, Z.H. (2005) Expression and characterization of human CB1 cannabinoid receptor in methylotrophic yeast Pichia pastoris. Protein Expr. Purif., 40, 60-70.

93 Sarramegna, V., Muller, I., Mousseau, G., Froment, C., Monsarrat, B., Milon, A., and Talmont, F. (2005) Solubilization, purification, and mass spectrometry analysis of the human mu-opioid receptor expressed in Pichia pastoris. Protein Expr. Purif., 43, 85-93.

94 André, N., Cherouati, N., Prual, C., Steffan, T., Zeder-Lutz, G., Magnin, T., Pattus, F., Michel, H., Wagner, R., and Reinhart, C. (2006) Enhancing functional production of $\mathrm{G}$ proteincoupled receptors in Pichia pastoris to levels required for structural studies via a single expression screen. Protein Sci., 15, 1115-1126.

95 Fraser, N.J. (2006) Expression and functional purification of a glycosylation deficient version of the human adenosine 2a receptor for structural studies. Protein Expr. Purif., 49, 129-137.

96 Noguchi, S. and Satow, Y. (2006) Purification of human $\beta 2$-adrenergic receptor expressed in methylotrophic yeast Pichia pastoris. J. Biochem., 140, 799-804.

97 Lundstrom, K., Wagner, R., Reinhart, C., Desmyter, A., Cherouati, N., Magnin,

\section{\begin{tabular}{l|l} 
References & 105
\end{tabular}}

T., Zeder-Lutz, G., Courtot, M., Prual, C., André, N., Hassaine, G., Michel, H., Cambillau, C., and Pattus, F. (2006) Structural genomics on membrane proteins: comparison of more than 100 GPCRs in 3 expression systems. J. Struct. Funct. Genomics, 7, 77-91.

98 Yang, G., Liu, T., Peng, W., Sun, X., Zhang, H., Wu, C., and Shen, D. (2006) Expression and localization of recombinant human EDG-1 receptors in Pichia pastoris. Biotechnol. Lett., 28, 1581-1586.

99 Yang, G.X., Liu, T.L., Zhang, H., Wu, C.Q., and Shen, D.L. (2006) Expression and localization of recombinant human B2 receptors in the methylotrophic yeast Pichia pastoris. Genetika, 42, 728-731.

100 Shukla, A.K., Haase, W., Reinhart, C., and Michel, H. (2007) Heterologous expression and characterization of the recombinant bradykinin B2 receptor using the methylotrophic yeast Pichia pastoris. Protein Expr. Purif., 55, 1-8.

101 Zhang, R., Kim, T.K., Qiao, Z.H., Cai, J., Pierce, Jr, W.M., and Song, Z.H. (2007) Biochemical and mass spectrometric characterization of the human CB2 cannabinoid receptor expressed in Pichia pastoris-importance of correct processing of the N-terminus. Protein Expr. Purif., 55, 225-235.

102 Magnin, T., Fiez-Vandal, C., Potier, N., Coquard, A., Leray, I., Steffan, T., Logez, C., Alkhalfioui, F., Pattus, F., and Wagner, R. (2008) A novel, generic and effective method for the rapid purification of $\mathrm{G}$ protein-coupled receptors. Protein Expr. Purif., 64, 1-7.

103 Muller, I., Sarramégna, V., Milon, A., and Talmont, F.J. (2010) The N-terminal end truncated mu-opioid receptor: from expression to circular dichroism analysis. Appl. Biochem. Biotechnol., 160, 2175-2186.

104 Talmont, F. (2009) Monitoring the human $\beta 1, \beta 2, \beta 3$ adrenergic receptors expression and purification in Pichia pastoris using the fluorescence properties of the enhanced green fluorescent protein. Biotechnol. Lett., 31, 49-55.

105 Hori, H., Sato, Y., Takahashi, N., Takio, K., Yokomizo, T., Nakamura, M., 
Shimizu, T., and Miyano, M. (2010) Expression, purification and characterization of leukotriene $\mathrm{B}_{4}$ receptor, BLT1 in Pichia pastoris. Protein Expr. Purif., 72, 66-74.

106 Blum, A., Martin, H.J., and Maser, E. (2000) Human 11ß-hydroxysteroid dehydrogenase 1 /carbonylreductase: recombinant expression in the yeast Pichia pastoris and Escherichia coli. Toxicology, 144, 113-120.

107 Newton-Vinson, P., Hubalek, F., and Edmondson, D.E. (2000) High-level expression of human liver monoamine oxidase B in Pichia pastoris. Protein Expr. Purif., 20, 334-345.

108 Binda, C., Newton-Vinson, P., Hubalek, F., Edmondson, D.E., and Mattevi, A. (2002) Structure of human monoamine oxidase $\mathrm{B}$, a drug target for the treatment of neurological disorders. Nat. Struct. Biol., 9, 22-26.

109 Li, M., Hubalek, F., Newton-Vinson, P., and Edmondson, D.E. (2002) High-level expression of human liver monoamine oxidase A in Pichia pastoris: comparison with the enzyme expressed in Saccharomyces cerevisiae. Protein Expr. Purif., 24, 152-162.

110 Nobel, C.S.I., Dunas, F., and Abrahmsén, L.B. (2002) Purification of full-length recombinant human and rat type $111 \beta$-hydroxysteroid dehydrogenases with retained oxidoreductase activities. Protein Expr. Purif., 26, 349-356.

111 Binda, C., Li, M., Hubalek, F., Restelli, N., Edmondson, D.E., and Mattevi, A. (2003) Insights into the mode of inhibition of human mitochondrial monoamine oxidase B from highresolution crystal structures. Proc. Natl. Acad. Sci. USA, 100, 9750-9755.

112 Ruf, A., Muller, F., D'Arcy, B., Stihle, M., Kusznir, E., Handschin, C., Morand, O.H., and Thoma, R. (2004) The monotopic membrane protein human oxidosqualene cyclase is active as monomer. Biochem. Biophys. Res. Commun., 315, 247-254.

113 De Colibus, L., Li, M., Binda, C., Lustig, A., Edmondson, D.E., and Mattevi, A. (2005) Three-dimensional structure of human monoamine oxidase A (MAO A): relation to the structures of rat MAO A and human MAO B. Proc. Natl. Acad. Sci. USA, 102, 12684-12689.

114 Dietrich, M., Grundmann, L., Kurr, K., Valinotto, L., Saussele, T., Schmid, R.D. and Lange, S. (2005) Recombinant production of human microsomal cytochrome P450 2D6 in the methylotrophic yeast Pichia pastoris. ChemBioChem., 6, 2014-2022

115 Liu, W., Kamensky, Y., Kakkar, R., Foley, E., Kulmacz, R.J., and Palmer, G. (2005) Purification and characterization of bovine adrenal cytochrome $b_{56}$ expressed in insect and yeast cell systems. Protein Expr. Purif., 40, 429-439.

116 Matsuzaki, F. and Wariishi, H. (2005) Molecular characterization of cytochrome P450 catalyzing hydroxylation of benzoates from the white-rot fungus Phanerochaete chrysosporium. Biochem. Biophys. Res. Commun., 334, 1184-1190.

117 Kolar, N.W., Swart, A.C., Mason, J.I., and Swart, P. (2007) Functional expression and characterisation of human cytochrome P45017 $\alpha$ in Pichia pastoris. J. Biotechnol., 129, 635-644.

118 Martinez Molina, D., Wetterholm, A., Kohl, A., McCarthy, A.A., Niegowski, D., Ohlson, E., Hammarberg, T., Eshaghi, S., Haeggstrom, J.Z., and Nordlund, P. (2007) Structural basis for synthesis of inflammatory mediators by human leukotriene $\mathrm{C}_{4}$ synthase. Nature, 448 , 613-617.

119 Upadhyay, A.K. and Edmondson, D.E (2008) Characterization of detergent purified recombinant rat liver monoamine oxidase B expressed in Pichia pastoris. Protein Expr. Purif., 59, 349-356.

120 Wetterholm, A., Martinez Molina, D., Nordlund, P., Eshaghi, S., and Haeggström, J.Z. (2008) High-level expression, purification, and crystallization of recombinant rat leukotriene $\mathrm{C}_{4}$ synthase from the yeast Pichia pastoris. Protein Expr. Purif. 60, 1-6.

121 Wang, J. and Edmondson, D.E. (2010) High-level expression and purification of 
rat monoamine oxidase $\mathrm{A}$ (MAO A) in Pichia pastoris : comparison with human MAO A. Protein Expr. Purif., 70, 211-217.

122 Arslan, B.K. and Edmondson, D.E. (2010) Expression of zebrafish (Danio rerio) monoamine oxidase (MAO) in Pichia pastoris: purification and comparison with human MAO A and MAO B. Protein Expr. Purif., 70, 290-297.

123 Brucato, C.L., Birr, C.A., Bruguera, P., Ruiz, J.A., and Sanchez-Martınez, D. (2002) Expression of recombinant rabbit tissue factor in Pichia pastoris, and its application in a prothrombin time reagent. Protein Expr. Purif., 26, 386-393.

124 Gurkan, C. and Ellar, D.J. (2003) Expression in Pichia pastoris and purification of a membrane-acting immunotoxin based on a synthetic gene coding for the Bacillus thuringiensis Cyt2Aa1 toxin. Protein Expr. Purif., 29, 103-116.

125 Huang, Z., Zhang, T., Yang, J., Zhu, P., Du, G., and Cheng, K. (2005) Cloning and expression of human lectin-like oxidized low density lipoprotein receptor-1 in Pichia pastoris. Biotechnol. Lett., 27, 49-52.

126 Labarre, C., Van Tilbeurgh, H., and Blondeau, K. (2007) Pichia pastoris is a valuable host for the expression of genes encoding membrane proteins from the hyperthermophilic Archeon Pyrococcus abyssi. Extremophiles, 11, 403-413.

127 Jamshad, M., Rajesh, S., Stamataki, Z., McKeating, J.A., Dafforn, T., Overduin, M., and Bill, R.M. (2008) Structural characterization of recombinant human CD81 produced in Pichia pastoris. Protein Expr. Purif., 57, 206-216.

128 Egawa, K., Shibata, H., Yamashita, S., Yurimoto, H., Sakai, Y., and Kato, H. (2009) Overexpression and purification of rat peroxisomal membrane protein 22, PMP22, in Pichia pastoris. Protein Expr. Purif., 64, 47-54.

129 Vos, W.L., Vaughan, S., Lall, P.Y., McCaffrey, J.G., Wysocka-Kapcinska, M. and Findlay, J.B.C. (2010) Expression and structural characterization of peripherin/RDS, a membrane protein

\section{\begin{tabular}{l|l} 
References & 107
\end{tabular}}

implicated in photoreceptor outer segment morphology. Eur. Biophys. J., 39, 679-688.

130 Vlahopoulos, S., Gritzapis, A.D., Perez, S.A., Cacoullos, N., Papamichail, M., and Baxevanis, C.N. (2009) Mannose addition by yeast Pichia Pastoris on recombinant HER-2 protein inhibits recognition by the monoclonal antibody herceptin. Vaccine, 27, 4704-4708.

131 Gustafsson, C., Govindarajan, S., and Minshull, J. (2004) Codon bias and heterologous protein expression. Trends Biotechnol., 22, 346-353.

132 Singh, S., Gras, A., Fiez-Vandal, C., Ruprecht, J., Rana, R., Martinez, M., Strange, P.G., Wagner, R., and Byrne, B. (2008) Large-scale functional expression of WT and truncated human adenosine $\mathrm{A}_{2 \mathrm{~A}}$ receptor in Pichia pastoris bioreactor cultures. Microb. Cell Fact., 7, 28.

133 Talmont, F., Sidobre, S., Demange, P., Milon, A., and Emorine, L.J. (1996) Expression and pharmacological characterization of the human mu opioid receptor in the methylotrophic yeast Pichia pastoris. FEBS Lett., 394, 268-272.

134 Cid, G.M., Nugent, P.G., Davenport, A.P., Kuc, R.E., and Wallace, B.A. (2000) Expression and characterization of the human endothelin-A-receptor in Pichia pastoris: influence of $\mathrm{N}$-terminal epitope tags. J. Cardiovasc. Pharmacol., 36, S55-S57.

135 Brillet, K., Perret, B.G., Klein, V., Pattus, F., and Wagner, R. (2008) Using EGFP fusions to monitor the functional expression of GPCRs in the Drosophila Schneider 2 cells. Cytotechnology, 57, 101-109.

136 Yu, Z.W. and Quinn, P.J. (1994) Dimethyl sulphoxide: a review of its applications in cell biology. Biosci. Rep., 14, 259-281.

137 Bernier, V., Lagacé, M., Bichet, D.G., and Bouvier, M. (2004) Pharmacological chaperones: potential treatment for conformational diseases. Trends Endocrinol. Metab., 15, 222-228.

138 Zeder-Lutz, G., Cherouati, N., Reinhart, C., Pattus, F., and Wagner, R. (2006) Dot-blot immunodetection as a versatile and high-throughput assay to evaluate 
recombinant GPCRs produced in the yeast Pichia pastoris. Protein Expr. Purif., 50, 118-127.

139 Aguilar-Uscanga, B. and François, J.M. (2003) A study of the yeast cell wall composition and structure in response to growth conditions and mode of cultivation. Lett. Appl. Microbiol., 37, 268-274.

140 Wagner, S., Klepsch, M.M., Schlegel, S., Appel, A., Draheim, R., Tarry, M., Högbom, M., van Wijk, K.J., Slotboom, D.J., Persson, J.O., and de Gier, J.W. (2008) Tuning Escherichia coli for membrane protein overexpression. Proc. Natl. Acad. Sci. USA, 105, 14371-14376.
141 Bonander, N., Darby, R.A., Grgic, L., Bora, N., Wen, J., Brogna, S., Poyner, D.R., O'Neill, M.A., and Bill, R.M. (2009) Altering the ribosomal subunit ratio in yeast maximizes recombinant protein yield. Microb. Cell. Fact., 8, 10. 142 Gasser, B., Saloheimo, M., Rinas, U., Dragosits, M., Rodríguez-Carmona, E., Baumann, K., Giuliani, M., Parrilli, E., Branduardi, P., Lang, C., Porro, D., Ferrer, P., Tutino, M.L., Mattanovich, D., and Villaverde, A. (2008) Protein folding and conformational stress in microbial cells producing recombinant proteins: a host comparative overview. Microb. Cell Fact., 7, 11. 


\title{
Keywords/Abstract
}

Dear Author,

Keywords and abstracts will not be included in the print version of your chapter but only in the online version.

Please check and/or supply keywords. If you supplied an abstract with the manuscript, please check the typeset version.

If you did not provide an abstract, the section headings will be displayed instead of an abstract text in the online version.

\section{Keywords:}

yeast; membrane protein; recombinant expression; methanol utilization; cell lysis

\begin{abstract}
:
Among the most widespread, popular, effective, and inexpensive microorganisms developed for heterologous expression, Pichia pastoris has become a system of choice not only for the production of cytosoluble and industrially relevant proteins, but also for a growing panel of eukaryotic membrane proteins expressed at levels compatible with structural studies. Up to now indeed, more than 150 different representative membrane proteins have been expressed in $P$. pastoris and led to acquiring of high-resolution structures for a dozen of them, making P. pastoris one of the most performant heterologous expression system for the structural studies of eukaryotic membrane proteins. This chapter gives a global overview on (i) how the $P$. pastoris system basically operates, (ii) how it performs for the recombinant expression of membrane proteins, and (iii) the different strategies and tips that can be applied to improve the system.
\end{abstract}

